\title{
Solar Signals in CMIP-5 Simulations: The Ozone Response
}

L. L. Hood, ${ }^{\mathrm{a} *}$ S. Misios, ${ }^{\mathrm{b}}$ D. M. Mitchell, ${ }^{\mathrm{c}}$ E. Rozanov, ${ }^{\mathrm{d}, \mathrm{e}}$ L. J. Gray, ${ }^{\mathrm{c}, \mathrm{f}}$ K. Tourpali, ${ }^{\mathrm{b}}$ K. Matthes,${ }^{\mathrm{g}, \mathrm{h}}$

\author{
H. Schmidt, ${ }^{\mathrm{i}}$ G. Chiodo ${ }^{\mathrm{j}, \mathrm{k}}$ R. Thiéblemont, ${ }^{\mathrm{g}}$ D. Shindell, ${ }^{1}$ A. Krivolutsky, ${ }^{\mathrm{m}}$ \\ ${ }^{a}$ Lunar and Planetary Laboratory, University of Arizona, Tucson, Arizona, USA. \\ ${ }^{\mathrm{b}}$ Laboratory of Atmospheric Physics, Aristotle University of Thessaloniki, Thessaloniki, Greece. \\ ${ }^{\mathrm{c}}$ Atmospheric, Oceanic and Planetary Physics, University of Oxford, Oxford, UK. \\ ${ }^{\mathrm{d}}$ Physikalisch-Meteorologisches Observatorium, World Radiation Center, Davos Dorf, Switzerland. \\ ${ }^{\mathrm{e}}$ Institute for Atmospheric and Climate Science, ETH, Zurich, Switzerland. \\ ${ }^{\mathrm{f}}$ NERC, National Centre for Atmospheric Science (NCAS), UK. \\ ${ }^{\mathrm{g}}$ GEOMAR Helmholtz Centre for Ocean Research Kiel, Kiel, Germany. \\ ${ }^{\mathrm{h}}$ Christian-Albrechts Universität zu Kiel, Kiel, Germany. \\ ${ }^{\mathrm{i}}$ Max Planck Institute for Meteorology, Hamburg, Germany. \\ ${ }^{\mathrm{j}}$ Departamento Fisica de la Tierra II, Universidad Complutense de Madrid, Madrid, Spain. \\ ${ }^{\mathrm{k}}$ Applied Physics and Applied Mathematics, Columbia University, New York, New York, USA. \\ ${ }^{1}$ Nicholas School of the Environment, Duke University, Durham, North Carolina, USA.
}

${ }^{\mathrm{m}}$ Laboratory for Atmospheric Chemistry and Dynamics, Central Aerological Observatory, Moscow, Russia.

*Correspondence to: LPL, Univ. of Arizona, 1629 E. University Blvd., Tucson, Arizona 85721 USA. E-mail:lon@1pl.arizona.edu

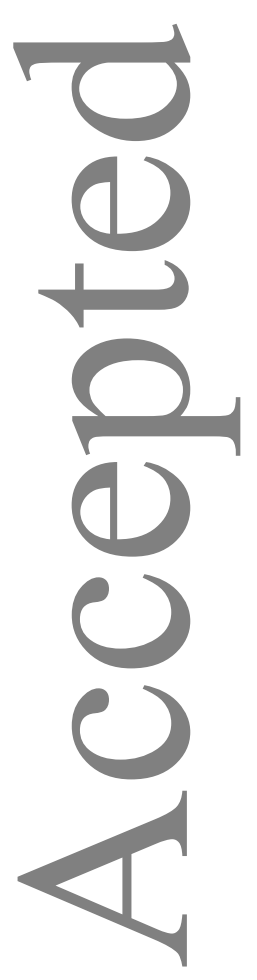

A multiple linear regression statistical method is applied to model data taken from the Coupled Model Intercomparison Project, phase 5 (CMIP-5) to estimate the 11-yr solar cycle responses of stratospheric ozone, temperature, and zonal wind during the 1979-2005 period. The analysis is limited to the six CMIP-5 models that resolve the stratosphere (high-top models) and that include interactive ozone chemistry. All simulations assumed a conservative 11-yr solar spectral irradiance (SSI) variation based on the NRL model. These model responses are then compared to corresponding observational estimates derived from two independent satellite ozone profile data sets and from ERA Interim Reanalysis meteorological data. The models exhibit a range of 11-yr responses with three models (CESM1-WACCM, MIROC-ESM-CHEM, and MRI-ESM1) yielding substantial solar-induced ozone changes in the upper stratosphere that compare favorably with available observations. The remaining three models do not, apparently because of differences in the details of their radiation and photolysis rate codes. During winter in both hemispheres, the three models with stronger upper stratospheric ozone responses produce relatively strong latitudinal gradients of ozone and temperature in the upper stratosphere that are associated with accelerations of the polar night jet under solar maximum conditions. This behavior is similar to that found in the satellite ozone and ERA Interim data except that the latitudinal gradients tend to occur at somewhat higher latitudes in the models. The sharp ozone gradients are dynamical in origin and assist in radiatively enhancing the temperature gradients, leading to a stronger zonal wind response. These results suggest that simulation of a realistic solar-induced variation of upper stratospheric ozone, temperature and zonal wind in winter is possible for at least some coupled climate models even if a conservative SSI variation is adopted.

C) 2013 Royal Meteorological Society
Words: $\quad$ SolarMIP, solar, stratosphere, ozone, CMIP-5, natural variability

This article has been accepted for publication and undergone full peer review but has not been through the copyediting, typesetting, pagination and proofreading process, which may lead to differences between this version and the Version of Record. Please cite this article as doi: $10.1002 /$ qj. 2553 


\section{Introduction}

As reviewed by Mitchell et al. (2014a) (hereafter referred to as Paper 1), the stratosphere containing the ozone layer represents a key link through which solar variability can produce perturbations 5 of tropospheric circulation. Solar influences on surface climate can, in principle, be due either to solar irradiance variations or changes in corpuscular radiation (energetic charged particles), or both (see, e.g., section 4 of the review by Gray et al. 2010). Influences of solar irradiance variability can be further divided into a so-called "bottom-up" category, involving direct penetration of solar radiation at wavelengths greater than about $300 \mathrm{~nm}$ to the lower troposphere, and a "top-down" category, involving effects of solar ultraviolet (UV) radiation on the upper atmosphere with indirect dynamical effects at lower levels. Because of the 5 important role of ozone, which is mainly produced by solar UV radiation, in radiatively heating the stratosphere and because solar UV variability is relatively large (up to $\sim 6 \%$ near $200 \mathrm{~nm}$ oyer an 11-yr cycle compared to $\sim 0.1 \%$ at wavelengths $>300$ m), top-down solar irradiance forcing is believed to be a non20 negligible component of solar-induced climate variability (Haigh 1994; 2003; Kodera and Kuroda 2002; Matthes et al. 2006; Meehl et al. 2009; Hood et al. 2013; Gray et al. 2013).

There are a number of sources of uncertainty in designing a general circulation model (GCM) that is able to simulate the bserved top-down component of solar irradiance-induced climate 65 change. These include uncertainties in solar spectral irradiance (SSI) variability itself, uncertainties in observational estimates for solar-induced stratospheric and surface climate response, and unlcertainties in the model formulation (see section 2.2 below).

The nature and magnitude of SSI variability has been a topic 70 increased attention during the last decade. Due to a lack of direct, long-term measurements of SSI, proxy-based models have previously been developed by several groups using indirect measurements such as sunspot area, the solar $10.7 \mathrm{~cm}$ radio flux 35 (F10.7), and the solar Mg II core-to-wing ratio (see the review 75 top models.

by Ermolli et al. 2013). These SSI models have been extensively employed in climate model simulations. For example, the SSI model developed at the U.S. Naval Research Laboratory (NRL SSI; Lean et al. 1995; Lean 2000; Wang et al. 2005) has been
40 adopted for use by most models in the most recent Coupled Model Intercomparison Project (CMIP-5) (Taylor et al. 2012).

New direct satellite-based measurements of SSI began to be obtained in 2003 by the SORCE (SOlar Radiation and Climate Experiment) (e.g., Harder et al. 2009). As reviewed by Ermolli et 45 al. (2013), the SORCE measurements differ in major ways from the proxy-based models and some of these differences may be a consequence of instrument degradation with time (e.g., Lean and DeLand 2012). In particular, a large SSI decrease in the 200 to 320 $\mathrm{nm}$ range was measured by SORCE during the decline of solar 50 cycle 23 that was four to six times larger than estimated by proxybased models. Ermolli et al. (2013) conclude that a lower limit on the magnitude of the SSI solar cycle variation is represented by the NRL SSI model while the SORCE measurements may represent an upper limit. However, results of recent efforts to account for 55 and correct instrument degradation effects in the SORCE SSI data (e.g., Woods 2012) suggest that the measured upper limit will be revised downward considerably.

This is the second in a series of analyses performed as part of the SPARC SOLARIS-HEPPA SolarMIP project (Solar Model Intercomparison Project). In Paper 1 (Mitchell et al. 2014a), multiple linear regression (MLR) was applied to assess the 11yr solar cycle component of both stratospheric and surface climate variability in the full suite of more than 30 models that contributed to the CMIP-5 comparison study. The analysis focused on the 6513 models that resolve the stratosphere (high-top models) and some evidence was obtained that these models are able to simulate better the surface response during northern winter than are lowtop models. However, as a whole, most of the high-top models did not reproduce either the magnitude or latitudinal gradients of solar-induced temperature responses in the upper stratosphere that are estimated using most meteorological reanalyses (see also Mitchell et al. 2014b). For this reason, the high-latitude dynamical responses that lead to significant top-down forcing of regional surface climate were also not well simulated in most of the highIn this paper, the model characteristics that yield a reasonable agreement of solar signals with available observations of the stratosphere are examined further. Specifically, multiple linear regression (MLR) is applied to compare in more detail solar 
80 signals in a subset of the 13 high-top CMIP-5 models consideredi20 in Paper 1, i.e., the 6 models that included coupled interactive ozone chemistry (as opposed to those whose stratospheric ozone variability was prescribed a priori). Attention is focused especially on the model response of stratospheric ozone (which 85 was not considered in Paper 1), as well as those of temperature andı2 zonal wind, and comparisons are made to selected observational stimates for the time period after 1979 when continuous global satellite remote sensing measurements began.

In many respects, this study builds on a previous work by Austin et al. (2008; see also Chapter 8 of SPARC-CCMVa1 ${ }^{130}$ needed.

2010). The latter authors analyzed solar cycle signals of ozone 13 and temperature in a series of simulations of coupled chemistry 8 elilmate models (i.e., general circulation models with coupled interactive chemistry) over various periods during the last half 5 of the 20th century. The employed models did not have coupled135 oceans but were forced at their lower boundaries using observed sea surface temperatures (SSTs). It was shown that the model ozone results were generally in agreement with observations at tropical latitudes (e.g., Soukharev and Hood 2006), yielding $100 \mathrm{a}$ double-peaked vertical structure with a maximum response $\mathrm{e}^{14}$ near 3-4 hPa of two to three per cent over a solar cycle, a minimum near $20 \mathrm{hPa}$, and a secondary maximum in the lower stratosphere. The upper stratospheric response is primarily a eonsequence of increased photolytic ozone production while the ower stratospheric response is believed to have a transport origin, ${ }^{14}$ resulting mainly from a slowing of the upwelling branch of the mean meridional (Brewer-Dobson) circulation near solar maxima Kodera and Kuroda 2002; Hood and Soukharev 2012).

However, a long-standing issue is whether part or all of 110 the tropical lower stratospheric $11-\mathrm{yr}$ response derived from ${ }^{15}$ observations during the satellite era may be a consequence of aliasing from the aerosol effects of two major volcanic eruptions, El Chichòn and Pinatubo, that fortuitously occurred following solar maxima in 1982 and 1991 (Solomon et al. 1996; Lee and 115 Smith 2003; Chiodo et al. 2014). Austin et al. (2008) tested this by comparing solar regression results with and without including an aerosol term in the MLR statistical model. They found little impact when analyzing model data over the 1960-2005 model period.
But some model chemistry schemes may be more sensitive to volcanic aerosol injections than others. For example, Dhomse et al. (2011) analyzed transient simulations using the SLIMCAT chemical transport model developed at the University of Leeds (Chipperfield 1999; 2006) over 1979-2005 and found that the modeled ozone solar response in the tropical lower stratosphere is amplified by aliasing from the volcanic eruptions. This was apparently because the model overestimates ozone losses during high aerosol loading periods. Further investigation of the volcanic aerosol aliasing issue in coupled climate models is therefore In section 2, the 6 high-top CMIP-5 models with interactive ozone chemistry are described and the MLR statistical method that is applied to the model data is summarized. Results of the analysis for annually averaged monthly solar regression coefficients for stratospheric ozone and temperature over the 1979-2005 period are presented and compared for the 6 models in section 2.5. Annual mean MLR analyses of model data are also carried out for time periods prior to 1979 when there were no major volcanic eruptions to assess further the sensitivity of the different model MLR results to volcanic aerosol aliasing during the 1979-2005 period. In section 3, previous efforts to estimate observationally the 11-yr solar-induced responses of stratospheric ozone, temperature, and zonal wind using data acquired after the initiation of continuous global satellite measurements in 1979 are first briefly reviewed. Then, selected observations-based estimates for these responses are presented for comparison with the model results. Next, the 11-yr solar signals in ozone, temperature, and zonal wind for the 6 models are examined in more detail for the northern early winter (Nov.-Dec.) and southern mid-winter (Jul.-Aug.) periods when observations indicate the strongest solarinduced latitudinal gradients in ozone/temperature and the largest enhancements of the polar night jet in both hemispheres. A summary and further discussion are given in section 4 .

\section{Models, Statistical Method, and Annual Mean Results}

55 2.1. Models

Table 1 lists the 6 high-top CMIP-5 models with interactive chemistry that are considered here. The institutes that were mainly 
responsible for producing these models are as follows: CESM1-

WACCM - U.S. National Center for Atmospheric Research,

160 Boulder, Colorado; MIROC-ESM-CHEM - University of Tokyo200 also comparable (several degrees of latitude or longitude at low

NIES, and JAMSTEC, Japan; MRI-ESM1 - Meteorological

Research Institute of Japan, Tsukuba City, Japan; GFDL-

CM3 - U.S. National Oceanic and Atmospheric Administration,

Geophysical Fluid Dynamics Laboratory, Princeton, New Jersey;

65 GISS-E2-H and GISS-E2-R - U.S. National Aeronautics ande05

Space Administration, Goddard Institute for Space Studies, New

York, New York. The two GISS models differ only in the nature of the coupled ocean model (Shindell et al. 2013). The GISS-E2R model used the "Russell" ocean (Russell et al. 1995) while the GISS-E2-H model used the Hybrid Coordinate Ocean Model (Sum10 least one recent reference for each model.

and Bleck 2006). All models were required to produce at least onle "historical" simulation over the 1850 to 2005 period with observed forcing consisting of solar spectral irradiance variations, volcanic sulfate aerosol, and greenhouse gas emissions (Taylor 175 et al. 2012). Effects of energetic charged particle precipitation were generally not included, except for WACCM, which has $a_{215}$ parameterization for increased odd nitrogen production in the thermosphere as a function of the geomagnetic Kp index (Marsh et a4 2007). All of the models considered here adopted the NRL SSI 180 model (Wang et al. 2005). Two of the models (CESM1-WACCM and GFDL-CM3) also scaled the total solar irradiance (TSI) by a constant factor of 0.9965 to agree with SORCE Total Irradiance constant factor of 0.9965 to agree with SOR
Monitor measurements (Kopp et al. 2005).

In the table, column 2 lists the number of ensemble members 185 that were available for analysis for the period after 1979. Three of the models (GFDL-CM3, GISS-E2-H, and GISS-E2-R) were225 applied to produce an ensemble of 5 historical simulations each. The remaining three (CESM1-WACCM, MIROC-ESM-CHEM, MRI-ESM1) performed one historical simulation each. In 190 addition, CESM1-WACCM carried out three shorter simulations for the 1955-2005 period with initial conditions taken from the230 single historical run (Marsh et al. 2013). Therefore, a total of 4 members are available for CESM1-WACCM for the period after 1979 when continuous global satellite observations became 195 available. Columns 3 and 4 list the approximate vertical and horizontal spatial resolutions of each model in the stratosphere235 the 40-60 km layer is related to $\mathrm{O}_{2}$ absorption in the $121-200$ $(\sim 3 \mathrm{hPa})$. The vertical resolutions at this level are comparable latitudes) except for MRI-ESM1, which has a higher resolution near 1 degree. Column 5 lists the approximate model tops in $\mathrm{km}$. These range from $\sim 140 \mathrm{~km}$ for CESM1-WACCM to $\sim 66 \mathrm{~km}$ for the two GISS models. Column 6 indicates whether each model generated (spontaneous) or whether it is forced (nudged) to agree with observational constraints. Four of the models have no QBO while MIROC-ESM-CHEM has a spontaneous QBO and CESM1-WACCM has a nudged QBO. Finally, column 7 lists at

\subsection{Model Radiation and Photolysis Rate Codes}

According to published descriptions, all of the 6 coupled climate models considered here used up-to-date interactive chemistry schemes. The main characteristics of the chemistry schemes for 5 of the 6 models (CESM1-WACCM, MIROC-ESM-CHEM, GFDL-CM3, GISS-E2-R, and GISS-E2-H) have been previously described in detail by Eyring et al. (2013; see their Appendix A). The chemistry scheme used in the MRI-ESM1 model, which provided data to the CMIP-5 archive at a later time, has been 20 summarized by Yukimoto et al. (2011; see also Shibata et al. 2005 and Deushi and Shibata 2010). In addition, the model radiation codes, including methods for simulating heating from volcanic aerosols in the lower stratosphere, are described in detail in the references listed in Table 1.

However, the modeled response of stratospheric ozone and temperature to 11-yr SSI forcing depends strongly on the detailed treatment of the solar UV irradiance in the 120-300 nm spectral range. Experiments using a 1-D radiative-convective-chemical model presented by Shapiro et al. (2013; see their Figure 2) are helpful for demonstrating that this is the case. In particular, they showed using the NRL SSI data set that the increase in ozone mixing ratio in the stratosphere caused by an increase in solar $\mathrm{UV}$ radiation is mainly due to enhanced ozone production by $\mathrm{O}_{2}$ photolysis with a maximum near $40 \mathrm{~km}$ altitude. The increase in $\mathrm{nm}$ interval (Schumann-Runge bands), while below $40 \mathrm{~km}$ the 
main spectral contribution is from the Herzberg continuum (200$242 \mathrm{~nm})$. A negative ozone response is expected in the middle mesosphere, driven by the increase of hydrogen radicals resulting 240 from water vapor photolysis by SSI in the SRB and at the Lyman-

$\alpha$ line. Both the positive ozone response centered near $40 \mathrm{~km}$ anckso calculates the heating rates due to ozone and molecular oxygen the negative response peaking in the middle mesosphere $(\sim 68$ $\mathrm{km})$ have been confirmed observationally using satellite remote ensing measurements on the solar rotational ( 27-day) time scale (e.g., Hood 1986, Keating et al. 1987, Hood et al. 1991). The absorption at the Lyman- $\alpha$ wavelength by $\mathrm{O}_{2}$ is also responsible 285 for a strong expected ozone increase in the upper mesosphere. Ozone photolysis in the $240-300 \mathrm{~nm}$ spectral range leads to ozone loss partly compensating the influence of enhanced $\mathrm{O}_{2}$ photolysis 250 abbve $30 \mathrm{~km}$.

The expected temperature response to an enhancement of 29 solar UV radiation is always positive and has two maxima at the stratopause and mesopause (e.g., Shapiro et al. 2013). The mesopause maximum is defined mostly by oxygen absorption in 255 the SRB and in the Lyman- $\alpha$ line. In the 50-70 km layer, the SRB and Herzberg continuum contribution dominates, while below $50^{295}$ $\mathrm{km}$,

ozone absorption in the Herzberg continuum and Hartley bands (200-300 nm) is the main contributor to the overall heating. For regions where the influence of dynamics is not crucial (e.g., the tropical middle to upper stratosphere and lower mesosphere), differences in modeled ozone and temperature responses to increases in SSI can potentially be explained by different300 MIROC-ESM-CHEM representations of the photolysis and radiative heating responses. Therefore, a detailed consideration of the individual model codes 265 is necessary. It should be noted however that the magnitude of the thermal response depends not only on the details of the shortwave radiation codes but also on the quality of the long-wave part of the codes because the net temperature change is a balance betweeno solar heating and infrared cooling.

\section{CESM1-WACCM}

The model version participating in CMIP-5 is described by Marsh et al. (2013). For wavelengths $>200 \mathrm{~nm}$ and at altitudes310 the absorption by $\mathrm{O}_{3}$ and $\mathrm{O}_{2}$ is included. Photolysis rates below $65 \mathrm{~km}$, the heating rates are calculated using the scheme of Briegleb (1992), which is based on the two-stream delta275 Eddington approximation (see also Briegleb and Light 2007). The solar visible and UV (200-700 nm) spectrum is divided into 8 spectral intervals. At UV wavelengths (200-350 nm), only ozone absorption is taken into account to calculate heating rates. At altitudes above $65 \mathrm{~km}$, the WACCM radiation code also directly absorption in the UV (124-400 $\mathrm{nm})$. The employed spectral resolution in this case is much higher and the UV interval is divided into 40 spectral bins. At $65 \mathrm{~km}$, the two sets of heating rates are merged. The photolysis rates are calculated using a 5 look-up table which consists of photolysis rates pre-calculated with the Stratospheric and Tropospheric Ultraviolet and Visible (STUV) radiative transfer model as a function of solar zenith angle, column overhead ozone, surface albedo, temperature, and pressure (SPARC-CCMVal 2010, Table 6s-4). The model applies a 4-stream discrete ordinate approach for calculations in the spectral interval $120-750 \mathrm{~nm}$, divided into 100 spectral bins. The WACCM also includes photolysis rates in the SchumannRunge bands (Koppers and Murtaugh 1996; Minschwaner and Siskind 1993) and Lyman- $\alpha$ line (Chabrillat and Kockarts 1997). 5 A possible minor weakness of the applied codes is neglect of molecular oxygen absorption in the UV below $65 \mathrm{~km}$. However, the effect of this on the heating rate response for a nominal solar cycle SSI change is essentially negligible at these altitudes (see Figure 3 of Sukhodolov et al. 2014).

Radiative heating and photolysis rates are calculated using the radiation code described by Sekiguchi and Nakajima (2008). The radiative transfer solver is based on the two-stream approximation in the form of a discrete-ordinate/adding method and allows absorption is treated using a correlated k-distribution (CKD) approach. The entire solar spectrum is divided into 23 intervals but the most important ones for the stratosphere/mesosphere solar UV spectrum $(185-300 \mathrm{~nm})$ consists of 6 intervals where are calculated on-line using temperature and radiation fluxes computed in the radiation code considering absorption and multiple scattering (Watanabe et al. 2011). The cross-sections and 
quantum yields of the atmospheric species for each spectral bin 315 are calculated using optimized averaging.

Weaknesses of the applied code include absence of the Lyman$\alpha$ line and water vapor photolysis. This could potentially lead to some overestimation of the ozone response in the upper stratosphere due to absence of $\mathrm{H}_{2} \mathrm{O}$ photolysis in the SRB. At 320 altitudes above $60 \mathrm{~km}$, the neglect of the Lyman- $\alpha$ line would sult in problems in the simulation of both the ozone and temperature responses.

\section{MRI-ESM1}

The model version participating in CMIP-5 is described 325 by Adachi et al. (2011). The calculation of heating rates in this version is performed with the two-stream delta-Eddington approximation with the entire solar spectrum divided into $22^{365}$ spectral intervals (Yukimoto et al. 2011, 2012). The absorption of solar UV radiation by $\mathrm{O}_{2}$ and $\mathrm{O}_{3}$ is included following 330 Freidenreich and Ramaswamy (1999), which divides the spectrum from 173 to $400 \mathrm{~nm}$ into 11 intervals. Absorption in the molecular lines is treated using a CKD approach. The photolysis rate (calcula culation is based on the scheme applied in the NCAR 2-D model SOCRATES (Huang et al. 1998) and includes all reactions $\sqrt{3}$

335 important for the stratosphere and mesosphere. The only obvious weaknless of the radiation code is the absence of the Lyman- $\alpha$ line. GFDL-CM3

The model version participating in CMIP-5 is described by Donner et al. (2011). The applied radiation code is based on an 340 original algorithm presented by Freidenreich and Ramaswamy (1999). To improve performance, the code was slightly simplified by reducing the total number of spectral intervals covering thes8 Specifically, zonal mean climatological ozone profiles were solar spectrum from 25 to 18 . However, in the UV range (173-300 $\mathrm{nm})$, the number of intervals remains the same as in the original 345 scheme (Anderson et al. 2004). Clear-sky photolysis rates are calculated using a multivariate interpolation table derived from the TUV model of Madronich and Flocke (1998), with an adjustment38 applied for the effects of large-scale clouds. As in MRI-ESM1, the only obvious weakness of the radiation code is the absence of 350 the Lyman- $\alpha$ line. However, it appears that the applied photolysis rate calculation scheme was designed mostly for tropospheric applications so it is possible that some aspects of $\mathrm{O}_{2}$ photolysis could be incompletely represented because this reaction is not important in the troposphere.

\section{GISS-E2-H and GISS-E2-R}

The model versions participating in CMIP-5 are described by Schmidt et al. (2014). As noted in section 2.1, the $\mathrm{H}$ and $\mathrm{R}$ versions differ only in the nature of the coupled ocean model. The calculation of heating rates is based on the Lacis and Hansen 360 (1974) parameterization, which considers solar UV absorption only by ozone. The photolysis rates are calculated using the Fast_J2 code of Bian and Prather (2002), which takes into account the model distribution of clouds, aerosols, and ozone. The scheme was improved by adding photolysis of water and NO at high 65 altitudes. The weakness of the applied radiation code is absence of oxygen absorption, which is very important in the upper stratosphere/mesosphere. Possible incomplete representation of the SRB and Lyman- $\alpha$ line in the Fast_J2 code could also lead to an underestimation of the positive ozone and temperature response 370 above $40 \mathrm{~km}$. This underestimation could be enhanced by the added photolysis of water vapor, which provides additional active hydrogen during solar maximum years.

\subsection{Long-Term Mean Ozone, Temperature, and Zonal Wind}

Prior to discussing the 11-year solar signals in the models, it is 375 first useful to compare long-term mean ozone, temperature, and zonal winds for the individual models to available observationsbased estimates. Figure S1a of the supplementary material shows the annual and zonal mean ozone at latitudes up to $80^{\circ}$ derived from observations over 1980-1991 by Fortuin and Kelder (1998). estimated using a combination of balloon (ozonesonde) data at levels below $10 \mathrm{hPa}$ and satellite observations from the Solar Backscattered Ultraviolet (SBUV) and Total Ozone Mapping Spectrometer (TOMS) instruments on Nimbus 7. A peak annual mean volume mixing ratio of $\sim 9.5 \mathrm{ppmV}$ occurs in the equatorial middle stratosphere at $32-35 \mathrm{~km}$ altitude. Figure $\mathrm{S} 1 \mathrm{~b}$ shows the annual mean temperature calculated from the ERA-Interim Reanalysis data set over the 1979-2012 period after adjustment to minimize artificial discontinuities as described in the Appendix. 
390 Results are shown up to $1 \mathrm{hPa}$, which is the highest level available for public access. The cold tropical tropopause has a mean temperature of less than $195 \mathrm{~K}$ while the stratopause temperature is more than 265 K. Finally, Figures S1c,d show the mean zonal wind for the months of December and July calculated from the 395 same reanalysis data set. Near $1 \mathrm{hPa}$, the polar night jet peaks at more than $55 \mathrm{~m} / \mathrm{s}$ near $45^{\circ} \mathrm{N}$ in December and reaches more than $\mathrm{m} / \mathrm{s}$ near $45^{\circ} \mathrm{S}$ in July.

Figures S2-S5 contain corresponding model results for comparison to Figure S1. Figure S2 shows the annual mean $1 \quad 5$ 400 ozone volume mixing ratio for the 6 models of Table 1, as calculated from the first archived historical simulation for each model. All of the models produce a reasonable annual mean ozone distribution, although the maximum in the middle stratosphere is noticeably more extended in latitude for the two GISS models. $405 \mathrm{In}$ the upper stratosphere near $1 \mathrm{hPa}$, the mean ozone mixing ratios according to the MIROC-ESM-CHEM and GFDL models are up to $30 \%$ larger than is estimated observationally in Figure sla $(\sim 4$ ppmV versus $\sim 3$ ppmV). Figure S3 shows the annual mean temperatures for the 6 models. All distributions are 410 again reasonable up to the stratopause. Above the stratopause, the MIROC-ESM-CHEM mean temperature drops rapidly with altitude, despite the larger ozone concentrations seen in Figure 2b. The stratopause temperatures for all models are comparable to those estimated from ERA-Interim data in Figure S1b. Figure 415 S4 shows the December mean zonal wind for the 6 models while Figure S5 shows the July mean zonal wind. Comparing the December model winds with the corresponding ERA-Interim winds of Figure S1c, all model wind distributions are reasonable. However, the peak wind near the stratopause for the two GISS 420 models has a somewhat low amplitude $(\sim 35 \mathrm{~m} / \mathrm{s}$ versus $\sim 50$ $\mathrm{m} / \mathrm{s}$ ) and is shifted equatorward compared to most of the other 460 models. Similarly, the July mean zonal wind for the two GISS models has a maximum amplitude of about half $(\sim 45 \mathrm{~m} / \mathrm{s})$ that estimated from observations in Figure S1d $(\sim 95 \mathrm{~m} / \mathrm{s})$. Peak July 425 zonal winds for the remaining models are near $90 \mathrm{~m} / \mathrm{s}$ except for 465 of the $\mathrm{Mg}$ II UV index, available from the Laboratory for CESM1-WACCM, which is somewhat high at $130 \mathrm{~m} / \mathrm{s}$. Possible reasons for these differences are briefly discussed in section 6.

\subsection{Method of Analysis}

As in Paper 1, in order to estimate the 11-yr solar component 30 of variability in the model ozone, temperature, and zonal wind monthly mean time series, we adopt a multiple linear regression (MLR) statistical approach. Because the solar signal evolves significantly as a function of season, monthly solar regression coefficients are calculated for comparison to corresponding 435 observational estimates described in section 3. The MLR model applied here differs from that applied in Paper 1 only in that the adopted solar predictor (basis function) is the solar $\mathrm{Mg}$ II coreto-wing ratio (or Mg II UV index), which is available since 1979 when continuous satellite measurements of SSI began. This index, which consists of a ratio that is insensitive to instrument-related drifts, is a measure of solar UV variations at wavelengths near $200 \mathrm{~nm}$ that are important for ozone production in the upper stratosphere (Heath and Schlesinger 1986; Viereck and Puga 1999). For example, the correlation coefficient between the $\mathrm{Mg}$ II index and the NRL SSI at $205 \mathrm{~nm}$ is 0.995. It is demonstrably more effective (see below and Figure S12) in representing solarinduced signals in observational stratospheric ozone data than other proxies such as total solar irradiance (TSI), F10.7, or sunspot number. In Paper 1, for the purpose of analyzing model 50 stratospheric temperature and zonal wind data, the NRL model TSI was adopted as the solar basis function because it, unlike $\mathrm{Mg}$ II, is available for the full historical period (1850-2005) and because the UV component of SSI was not represented uniformly in all of the CMIP-5 models.

Specifically, the adopted MLR model for a given atmospheric variable and month $X(i, t)$ is of the form:

$$
\begin{aligned}
X(i, t)= & \mu(i)+\beta_{\text {solar }} \operatorname{MgII}(i, t)+\beta_{\text {volcanic }} \operatorname{SATO}(i, t) \\
& +\beta_{\mathrm{QBO} 1} \mathrm{QBO} 1(i, t)+\beta_{\mathrm{QBO} 2} \mathrm{QBO} 2(i, t) \\
+ & \beta_{\text {ENSON}} 3.4(i, t)+\beta_{\text {trend }} \operatorname{GHG}(i, t)+\mathrm{r}(i, t)
\end{aligned}
$$

where $i$ is the month of the year $(i=1,2, \ldots, 12), t$ is the time in increments of years, $\mu(i)$ is the long-term mean for the $i$ th month, $\mathrm{Mg} \mathrm{II}(i, t)$ is the corresponding value Atmospheric and Space Physics at the University of Colorado (http://lasp.colorado.edu/lisird/mgii), $\operatorname{SATO}(i, t)$ is a measure of 
the volcanic aerosol concentration (updated from Sato et al. 1993), $\mathrm{QBO} 1(i, t)$ and $\mathrm{QBO} 2(i, t)$ are the first and second Empirical 470 Orthogonal Functions of the model equatorial $\left(5^{\circ} \mathrm{S}\right.$ to $\left.5^{\circ} \mathrm{N}\right)$ zonal mean zonal wind at levels from 5 to $70 \mathrm{hPa}$ in the stratosphere, $\mathrm{N} 3.4(i, t)$ is the Niño 3.4 index (defined as the model sea surfaces10 temperature anomalies in the region from $5^{\circ} \mathrm{S}$ to $5^{\circ} \mathrm{N}$ and from $120^{\circ} \mathrm{W}$ to $\left.170^{\circ} \mathrm{W}\right), \operatorname{GHG}(i, t)$ is a time series representative of concentration of well-mixed greenhouse gases, and $\mathrm{r}(i, t)$ is the residual noise term. The coefficients $\beta_{\text {solar }}, \beta_{\text {volcanic }}, \beta_{\mathrm{QBO} 1}$,

$\mathrm{P}_{\mathrm{QBO} 2}, \beta_{\mathrm{ENSO}}$, and $\beta_{\text {trend }}$ are determined by linear least squares515 egression. Note that the QBO1, QBO2, and N3.4 basis function time series must be calculated from the model data for each individual model prior to application of (1). For models with no $\mathrm{QBO}$, the QBO terms are set to zero. As described in more detail in Paper 1, to correct for autocorrelation of the model datas20 residuals after applying (1), we use the method of Tiao et al. 990) (see also Cochrane and Orcutt 1949 and Garny et al. 2007). 485 However, the correction is relatively minor since the year-to-year autocorrelation of the monthly residuals is not large.

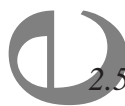

Annual Mean Model Results 1

Figure 1 shows annual averages of the monthly solar regression effidients calculated from model ozone data over the 1979-2005 490 period for all 6 models listed in Table 1. These averages are 530 produced by first calculating the monthly regression coefficients and standard deviations for each ensemble member for a given model (4 for CESM1-WACCM, 1 for MIROC-ESM-CHEM, 1 for MRI-ESM1, and 5 each for GFDL-CM3, GISS-E2-H, and GISS495 E2-R). The ensemble means are then calculated for each mode 535 valid solar proxy.

and month (see Figures S6-S11). Finally, the ensemble means of the coefficients and standard deviations for each of the 12 months are averaged together for each model at each grid point to produce Figure 1. The starting point of 1979 is determined by the 500 beginning of continuous satellite observations (section 3) whiles40 coefficients are obtained for 5 of the 6 models. Results for the end point of 2005 is determined by the final year of the CMIP5 simulations. Ozone regression results are only shown at altitudes above $16 \mathrm{~km}$ since the vast majority of the ozone column is in the stratosphere. Results are not shown above $54 \mathrm{~km}$ since for 4 of the
Ozone solar regression coefficients are expressed as the per cent change in ozone concentration or mixing ratio for a change in the $\mathrm{Mg}$ II core-to-wing ratio of 0.0169 . The latter value is roughly equivalent to a change in F10.7 of $\sim 130$ corresponds to a cycle that is about average for the 1940-2000 period but stronger-than-average for the 1850-1940 period. In the remainder of this paper, this change is referred to as solar "minimum to maximum" or "max - min". In this and subsequent figures, dark shaded areas indicate regions where the averaged monthly solar regression coefficients are greater than twice the averaged monthly standard deviations. These areas are statistically significant at approximately $95 \%$ confidence. Lighter shaded areas indicate regions where the coefficients are more than one averaged $68 \%$ confidence.

Figures S6-S11 show the monthly ensemble mean ozone solar regression coefficients for each of the 6 models that were averaged together to produce the annually averaged plots in Figure 1. Figure $525 \mathrm{~S} 12$ confirms that the Mg II solar UV index gives more significant ozone solar coefficient regression results for the CMIP-5 model ozone data over the 1979-2005 period. It compares the annually averaged monthly ozone solar regression coefficients obtained for the CESM1-WACCM model when the assumed solar basis function consists of (a) TSI; (b) F10.7; and (c) the solar Mg II UV index. Both the amplitude and statistical significance of the solar regression coefficients are largest when the Mg II UV index is used. Nevertheless, the TSI index used in Paper 1 for atmospheric variables other than ozone over the 1850-2005 period remains a

As seen in Figure 1, there is a wide range in the amplitude and statistical significance of the ozone solar regression results among the models, especially in the upper stratosphere. Despite the short 27-year analysis period, statistically significant solar models with little or no response in the upper stratosphere are shown in the lower panel (Figure $1 \mathrm{~d}$, e, and f). Overall, the least significant coefficients were obtained for GFDL-CM3 while the most significant coefficients were obtained for MRI-ESM1. 
only marginally significant $(1 \sigma)$ values obtained in the lower stratosphere. The two GISS-E2 models produce a significant ozone response with maximum averaged amplitude of $\sim 2 \%$ that is centered in the middle stratosphere near $10 \mathrm{hPa}(\sim 32 \mathrm{~km})$ while 550 the response above $2 \mathrm{hPa}$ is nearly zero.

The three models that do produce a significant averaged upper stratospheric response yield results shown in the top panel of Figure 1. The CESM1-WACCM response is centered at roughly $4 \mathrm{hPa}(\sim 38 \mathrm{~km})$ while the MIROC-ESM-CHEM and MRI-ESM1 555 responses are centered at a slightly higher level of $3 \mathrm{hPa}$ or $\sim 40595$ $\mathrm{km}$. In all three cases, the peak amplitude averaged over all months is near $3 \%$. Above the stratopause $(\sim 1 \mathrm{hPa})$, the MRI-ESM1 (1) response is largest $(>2 \%)$ at high latitudes in both hemispheres. As also seen in Figure 1, several models (CESM1-WACCM 560 and GISS-E2-H) produce strong and apparently significant ozone600 responses in the lower stratosphere $(\sim 50 \mathrm{hPa})$. On the other hand, MIROC-ESM-CHEM and MRI-ESM1 produce reduced and much less significant responses at this level, indicating that the modeled lower stratospheric ozone response could be 565 Sensitive to details of the model formulation. In particular, because605 the time period considered here includes two major volcanic I eruptions (El Chichòn in 1982 and Pinatubo in 1991) that followed solar maxima in 1980 and 1989, it is possible that the lower stratospheric ozone signal in many of the models of Figure 1 is 570 affected by aliasing, i.e., lack of complete orthogonality between6
the solar and volcanic aerosol basis function time series (Solomon et al. 1996; Lee and Smith 2003). If so, then the magnitude of the apparent lower stratospheric 11-yr ozone response in many of the models of Figure 1 could be a function of how sensitive 575 the simulated lower stratospheric chemistry and dynamics are to615 four or the latter two.

volcanic aerosol effects (e.g., enhanced heterogeneous chemical ozone losses or radiative heating).

The extent to which aliasing between the solar and volcanic aerosol regression coefficients may occur in a version of WACCM 580 (WACCM3.5) without a coupled ocean (forced using observed620 SSTs and sea ice concentrations) has recently been investigated by Chiodo et al. (2014). By carrying out simulations over the 19602004 period with and without including volcanic aerosol forcing, it was found that most of the apparent solar-induced variation of is due to the two major volcanic events mentioned above. It was therefore inferred that the part of decadal variability in tropical lower stratospheric observations that can be attributed to solar variability may be smaller than previously believed. This may 590 indeed be the case (see the next section).

However, the results of Figure 1 also suggest that any conclusions drawn from model simulations about the extent of volcanic aerosol aliasing in observations over the 1979-2005 period may depend on the model that is employed. To examine this possibility further, Figure S30 shows results of an MLR analysis of the same model ozone data over the 1955-1981 period (prior to the El Chichòn eruption). The 11-yr ozone responses for all models are somewhat weaker at most altitudes than that shown in Figure 1, possibly because of a relatively weak solar cycle 20, which peaked near 1970. But the most dramatic reduction in the response occurs in the lower stratosphere for 4 of the 6 models, CESM1-WACCM, GFDL-CM3, and the two GISS models. The remaining two models, MIROC-ESM-CHEM and MRI-ESM1, continue to show a lower stratospheric response that is proportionally of the same magnitude as obtained for the 19792005 period (i.e., the ratio of the lower stratospheric response to the upper stratospheric response is nearly the same). From the combination of Figures 1 and S25, it can be inferred that the former four models produce an 11-yr lower stratospheric ozone 0 response that is clearly affected by aliasing from the two volcanic aerosol injection events while the responses for the latter two are not so strongly affected. Based only on this comparison of model results, however, it is difficult to evaluate which set of models is best able to simulate the lower stratospheric response, the former Figure 2 shows corresponding results for the annually averaged monthly temperature solar regression coefficients, expressed as the change in Kelvin from solar minimum to maximum (defined above). The individual ensemble mean monthly temperature solar regression coefficients are plotted in Figures S13-S18 for the 6 models. The annual mean results of Figure 2 are not very different from those shown in Paper 1, which used TSI rather than Mg II as the solar predictor and which analyzed the full suite of CMIP-5 models. Nevertheless, we show them here for completeness. As 
the ozone results of Figure 1 since the ozone change contributes665 response (CESM1-WACCM, MIROC-ESM-CHEM, and MRIsignificantly to the radiative heating change from solar minimum to maximum in the stratosphere (e.g., Gray et al. 2009).

In the upper stratosphere, the three models in the top panel of 630 Figure 2 produce the strongest responses, exceeding $1 \mathrm{~K}$ near the stratopause. The GFDL-CM3 model produces the least significant

results with amplitudes of $\sim 0.5 \mathrm{~K}$ near the stratopause at most latitudes while the MRI-ESM1 model produces the strongest and most significant temperature response throughout the low-latitude 635 stratosphere, exceeding $1 \mathrm{~K}$ above the $2 \mathrm{hPa}$ level. The two GISS-E2 models produce a significant temperature response of intermediate amplitude $(>0.5 \mathrm{~K})$ at most levels above $\sim 30 \mathrm{hPa}$. In the lower stratosphere at levels between 20 and $50 \mathrm{hPa}$, all models except GFDL-CM3 produce an apparently significant 640 response of order $0.5 \mathrm{~K}$ or more from solar minimum to máximum. However, as discussed above for ozone, it is likely680 3. Comparisons With Observational Estimates that 11-yr signals in the lower stratosphere for many of these models are affected by aliasing from volcanic aerosol injections during the 1979-2005 period. To test this possibility, Figure S31 645 shows results of a similar analysis for the 1955-1981 period. The apparently significant subtropical CESM1-WACCM responses at the $50 \mathrm{hPa}$ level seen in Figure 2 are not present in Figure S31 and are replaced by a weakly significant equatorial response centered at about $20 \mathrm{hPa}$. The lower stratospheric responses for the MRI650 ESM1 model and the two GISS-E2 models seen in Figure 2 are no longer present in Figure S31. Only in the case of the MIROCESM-CHEM model does a weak lower stratospheric response remain in the 20-50 hPa tropical region. Thus, only MIROC-ESMCHEM and possibly CESM1-WACCM could be simulating a true solar-induced tropical lower stratospheric temperature response.

Turning to the monthly model ozone and temperature solar coefficients plotted in Figures S6-S11 and S13-S18, a seasonal695 and above the stratopause at low latitudes (e.g., Soukharev and evolution of the solar-induced signal is clearly present. In the summer hemisphere for all models, the thermal response in the 660 upper stratosphere tends to shift toward higher latitudes, reflecting the reduced solar-zenith angle during that season and the longer duration of daily solar heating at polar latitudes (midnight sun),700 However, for the models in the top panels of Figures 1 and 2 with a relatively large upper stratospheric ozone and temperature

ESM1), there is also a tendency for large negative latitudinal ozone and temperature gradients to develop at high latitudes in the winter hemisphere. A similar tendency for temperature averaged over all high-top models during northern winter was also shown in 70 Figure 7 of paper 1. Averaged over all 4 of the CESM1-WACCM ensemble members, the large negative ozone and temperature gradients are mainly seen in the southern hemisphere in June and July but are also present in the northern hemisphere winter for 2 of the 4 members (not shown). In the case of the single MIROCESM-CHEM simulation, it occurs in December at high northern latitudes and in July/August at high southern latitudes for both ozone and temperature. The same is true for the single MRI-ESM1 simulation. For the latter two models, the negative latitudinal gradients are noticeably larger in the southern hemisphere winter.

\subsection{Ozone}

Continuous global satellite remote sensing measurements of stratospheric ozone have been obtained since late 1978 (WMO 2007). These measurements, like those of SSI, are subject to 85 uncertainties including degradation with time and intercalibration offsets between different instruments. The longest continuous record of stratospheric ozone concentrations by a single instrument was obtained by the Stratospheric Aerosol and Gas Experiment (SAGE) II, beginning in November of 1984 and ending in August, 2005. The solar occultation measurement technique employed by SAGE yields a relatively good vertical resolution approaching $1 \mathrm{~km}$ (e.g., McCormick et al. 1989). Analyses of these data indicate substantial variations of 2 to $4 \%$ from solar minimum to maximum extending from $\sim 5 \mathrm{hPa}$ to Hood 2006; Randel and Wu 2007; Kyrölä et al. 2013; Remsberg 2014; see Figure 3c below). However, due to the sparse sampling of the SAGE solar occultation measurements, only annual mean regression coefficients can be accurately estimated.

A second long-term data set with more complete sampling but less continuity and less vertical resolution $(\sim 8 \mathrm{~km})$ has been constructed at the U.S. Goddard Space Flight Center by 
merging together vertical ozone soundings by a series of SBUV instruments on Nimbus 7 (late 1978 to 1990) and subsequent
To allow a more direct comparison with the annually averaged monthly model ozone solar regression coefficients of Figure 1

705 U.S. National Oceanic and Atmospheric Administration (NOAA) 45 and the monthly coefficients of Figures S6-S11, the analysis operational satellites (McPeters et al. 2013; Kramarova et al. of Soukharev and Hood (2006) was extended to calculate 2013). The data obtained by the Nimbus 7 SBUV instrument were at a nearly constant local time while data acquired with SBUV/2 monthly merged SBUV ozone regression coefficients using the same MLR model (1) that was applied to the CMIP-5 model instruments on the NOAA satellites beginning with NOAA 11 in data. Specifically, the monthly mean Version 8 merged SBUV 7101989 were more affected by orbital drifts that caused the local50 ozone profile data set covering 1979-2003 was reanalyzed to time of measurement to vary during many of these missions. In calculate individual monthly solar regression coefficients using the updated statistical model (1), including the more conservative istial trends since there is a significant diurnal variation of there is a significant diurnal variation of autocorrelation correction described in section 2 and Paper 1. The ENSO basis function in this case is the observed Niño 3.4 index ozone at these levels. Multiple linear regression (MLR) analyses of the merged SBUV data through 2003 yield a substantial annual55 and the two QBO empirical orthogonal functions are calculated mean solar cycle variation of 3 to $4 \%$ at $\sim 2 \mathrm{hPa}$ and above in the from the ERA Interim reanalysis data as described in Paper 1. upper stratosphere at low latitudes (Soukharev and Hood 2006; Tourpali et al. 2007). As shown in the latter references, seasonal e.g., northern winter and summer) mean regression coefficients The N3.4 time series is lagged by 3 months to account for the observed delay in the stratospheric response to surface ENSO variability (e.g., Hood et al. 2010). The analysis is limited to the 720 can also be estimated using the more densely sampled, merged 60 period prior to 2004 to allow direct comparisons with the results SBUV data set. However, as discussed further below, the SBUV esults have significant uncertainties imposed by the shortness of the data record (no more than 3.5 solar cycles) and the low vertical resolution of the individual profile measurements. of Soukharev and Hood (2006) and Tourpali et al. (2007) and to avoid any effects of a drift in the NOAA 16 orbit, which began in early 2004 .

Figure 3a shows the annually averaged SBUV monthly solar 725. A third data set of interest is that obtained by the Halogem65 regression coefficients to allow a direct comparison to the model Occultation Experiment (HALOE) on the Upper Atmosphere Research Satellite (UARS). Like SAGE, this experiment used he solar occultation technique but operated only from late 1991 to late 2005. HALOE retrieved ozone profiles on a pressure annually averaged coefficients of Figure 1. Specifically, Figure 3a was produced by averaging together the 12 monthly SBUV ozone solar regression coefficients and the corresponding standard deviations at each grid point. The individual monthly SBUV 730 coordinate while SAGE ozone was retrieved on height levels,770 solar regression coefficients are plotted in Figure S19. Regression which requires adoption of a long-term temperature record in order to convert the measurements to mixing ratios on pressure surfaces. Analyses of the HALOE ozone profile dataset yield somewhat reduced solar regression coefficients in the upper coefficients and standard deviations at a given grid point were calculated from the 25 monthly means over 1979-2003. Figure 3b shows the annual mean SBUV solar regression coefficients obtained by considering each monthly anomaly (monthly mean 735 stratosphere compared to those estimated from the longer SAGE75 minus long-term monthly mean) as an independent data point and merged SBUV records (Soukharev and Hood 2006; Remsberg $(25 \times 12=300)$. The annual mean coefficients of Figure 2008). As discussed in the latter references, these reduced coefficients appear to agree better with model estimates near and $3 \mathrm{~b}$ are more statistically significant than the annually averaged monthly coefficients of Figure 3a, as would be expected from above the stratopause than those derived from SAGE or SBUV. the increased number of data points. In both cases, the per cent 740 However, it is unclear whether the reduced coefficients are a 80 change in ozone from solar minimum to maximum is largest consequence of the more direct HALOE retrieval technique or of in the uppermost stratosphere, especially in the tropics and the shorter record length (14 years). at high latitudes in both hemispheres. In the tropical middle 
stratosphere $(\sim 4 \mathrm{hPa})$, the response is a minimum and is statistically insignificant. Positive responses are also obtained in 785 the extratropical middle stratosphere and in the lower stratospheres25 could be an artificial bias in these data toward higher altitudes. near $50 \mathrm{hPa}$. The annually averaged monthly and annual mean ozone solar regression coefficients in Figures $3 a, b$ are only marginally significant in the lower stratosphere. This differs from the results of Soukharev and Hood (2006) and Tourpali al. (2007), who found apparently significant annual means30 colefficients in much of the lower stratosphere. The reduced significance obtained here is probably due to the use of alternate asis functions for volcanic aerosol and the QBO, as well as to the more conservative autocorrelation correction. However, the monthly regression coefficients remain statistically significanto35 dutring certain months, especially July and August as seen in Figure S19. Also, analyses of column ozone, which is dominated by lower stratospheric ozone, as a function of longitude and atitude yield significant solar regression coefficients at low 800 latitudes during the northern summer and winter seasons (Hoods40 tropics only at levels above $2 \mathrm{hPa}(\sim 42 \mathrm{~km})$.

and Soukharev 2012).

Comparing the annually averaged monthly SBUV ozone solar regression coefficients of Figure $3 \mathrm{a}$ with the corresponding model coefficients of Figure 1, none of the models appears to yield an 1 805 ozone response that agrees to first order with that derived fromb45 the SBUV observations. None of the models produces a relative I minimum in the tropical response near $4 \mathrm{hPa}$, although CESM1WACCM produces a tropical minimum near the $20 \mathrm{hPa}$ level. The averaged monthly SBUV coefficients yield maxima near the 810 stratopause exceeding $6 \%$ in the tropics, decreasing to $\sim 4 \%$ at850 midd ddle latitudes, and increasing again to more than $6 \%$ at high latitudes. None of the models produces a response that maximizes near the tropical stratopause with reductions at midlatitudes. The 3 models in the top panel of Figure 1 do produce relatively large $815(>2 \%)$ ozone responses in the upper stratosphere but they $\operatorname{are}_{855}$ centered near 4, 3, and $3 \mathrm{hPa}$, respectively, while the SBUV response is centered above $1 \mathrm{hPa}$. The 3 models in the bottom panel of Figure 1 produce responses at even lower levels (centered at or below the $10 \mathrm{hPa}$ level).

820 However, some of the disagreements between Figure 3a andb60 weighted averages of the SAGE II results from Figure 3c at a Figure 1 may be a consequence of measurement uncertainties. Although the merged SBUV data set is the only available record
Evidence that this may be the case comes from a consideration of the annual mean solar regression coefficients obtained from SAGE data, which have much better vertical resolution $(\sim 1 \mathrm{~km}$ vs. $\sim 8 \mathrm{~km}$ for SBUV). Figure $3 \mathrm{c}$ shows the result of an analysis 2006) using the improved MLR model (1) and autocorrelation correction. In agreement with previous analyses (e.g., Randel and $\mathrm{Wu}$ 2007), the region of minimum tropical response based on SAGE data is centered near $10 \mathrm{hPa}(\sim 31 \mathrm{~km})$ while that of Figure SAGE-derived ozone solar regression coefficients exceed $2 \%$ and are statistically significant at all levels above $5 \mathrm{hPa}(\sim 36 \mathrm{~km})$ continuing up to at least $0.5 \mathrm{hPa}(\sim 54 \mathrm{~km})$. On the other hand, the annual mean SBUV coefficients of Figure $3 b$ exceed $2 \%$ in the Independent evidence that the ozone 11-yr solar regression coefficients derived from merged SBUV data are underestimated at levels below $2 \mathrm{hPa}$ in the tropics has also been presented by Fioletov (2009). He predicted 11-yr ozone variations at low latitudes using the observed ozone response to short-term solar rotational ( 27-day) UV variations and then compared these projected variations to observed decadal variations in data from the individual SBUV instruments. It was found (see his Figure 12) that the projected variation remained significant down to thitudes as low as $33 \mathrm{~km}$ even though no response was detectable in the combined SBUV time series. Also, the SBUV data from the Nimbus 7 time period (1979-1990) contained an anomalously large 11-yr variation at altitudes above $44 \mathrm{~km}$ compared to the projected variation and to that recorded during later solar cycles.

Accepting the possibility that the actual observed ozone response extends downward to at least the $5 \mathrm{hPa}$ level in the tropics, the three modeled ozone responses in the top panel of Figure 1 compare more favorably with the observations. To illustrate this, Figure 4 plots tropical $\left(25^{\circ} \mathrm{S}\right.$ to $\left.25^{\circ} \mathrm{N}\right)$ areaseries of pressure levels up to $1 \mathrm{hPa}(\sim 48 \mathrm{~km})$ together with corresponding averages of the model results of Figure 1. As 
seen in Figure 4a, the three models in the top panel of Figure 1 yield ozone response profiles that fall well within the $2 \sigma$ error 865 bars of the tropical mean SAGE II solar coefficients. As seen in Figure $4 \mathrm{~b}$, the remaining models produce tropical mean uppergo5 from solar minimum to maximum as defined in section 2.5 . The stratospheric ozone responses that are outside of the $2 \sigma$ error bars at altitudes above $40 \mathrm{~km}$. Also, the altitude dependence of the solar ozone response for the latter models differs noticeably from that stimated from the SAGE II data.

\subsection{Temperature}

Continuous global satellite remote sensing measurements of atmospheric temperature also began in the late 1970's. In Paper 1, model temperature solar responses were compared to estimates derived from the three most recent reanalysis meteorological ${ }^{91}$ ata sets, MERRA, ERA-Interim, and JRA-55 (Mitchell et al. 2014b). As discussed in Paper 1, a maximum solar-induced temperature response in the reanalyses of several Kelvin is obtained at low latitudes well above the stratopause $(\sim 0.5 \mathrm{hPa})$, 880 whereas the maximum expected theoretical response is about ${ }^{920}$ half this amplitude and is centered near the stratopause (Gray al. 2009). It was therefore suggested that increased errors in the reanalyses at levels above $1 \mathrm{hPa}$ where data assimilation poorly constrained by observations may be responsible for nlexpectedly large apparent solar signal. A comparison of 25 direct satellite Stratospheric Sounding Unit (SSU) measurements with reanalysis temperature time series supported this inference (Mitchell et al. 2014b).

Here, we consider specifically temperature and zonal wind 890 data from one of the reanalyses, ERA Interim (Dee et al.930 2011), which are publicly available to a level of $1 \mathrm{hPa}$ (http://apps.ecmwf.int/datasets). As described in the Appendix (see also McLandress et al. 2014), at least one source of errors in this data set, step changes in upper stratospheric temperature 895 occurring near the times of major changes in instrumentation org35 processing of assimilated data, can be empirically minimized to produce an "adjusted" ERA Interim zonal mean temperature data set. Such an empirical minimization procedure is not generally applicable to other reanalyses (e.g., MERRA) because step 900 changes were usually replaced with ramp functions in the archived 940 lower stratospheric subtropical temperature response maxima data sets. agree qualitatively with responses seen in the SBUV data

Figure 5a shows the annually averaged monthly solar temperature regression coefficient derived from the adjusted ERA data over the 1979-2012 period, expressed as the change in Kelvin entire available 34-year record is considered rather than only the 1979-2005 period because the results change only slightly as compared to the shorter record and the statistical significance is improved. The individual monthly ERA Interim solar temperature 910 regression coefficients are plotted in Figure S20. Figure 5b shows the corresponding annual mean coefficient obtained when all available data points $(12 \times 34=408)$ are analyzed. The annual mean tropical upper stratospheric response is larger in peak 5 averaged monthly response of Figure 5a has a peak amplitude of $\geq 1 \mathrm{~K}$ and is only marginally significant. Overall, Figure $5 \mathrm{~b}$ agrees well with previous studies, which analyzed the ERA-40 reanalysis data set through 2001 or extensions thereof (e.g., Crooks and Gray 2005; Frame and Gray 2010). It also agrees well with an alternate analysis of ERA Interim data by Mitchell et al. (2014b). As shown in their Figure 7, the peak response in the tropics occurs near $2 \mathrm{hPa}$ and the high-latitude maxima at $1 \mathrm{hPa}$ in Figure $5 \mathrm{~b}$ extend up to $0.3 \mathrm{hPa}(\sim 55 \mathrm{~km})$.

Comparing the annual ERA temperature results of Figure 5 25 with the annual observational ozone results of Figure 3, several similarities are notable. First, in the tropics, the ozone response is largest in the upper stratosphere (down to $\sim 2 \mathrm{hPa}$ for $\mathrm{SBUV}$ and down to $\sim 5 \mathrm{hPa}$ for $\mathrm{SAGE}$ ) while the temperature response is also largest in the tropical upper stratosphere ( 1 to $3 \mathrm{hPa}$ ). Second, at high latitudes near the $1 \mathrm{hPa}$ level, the temperature response maxima of order $2 \mathrm{~K}$ compare favorably with the SBUV ozone response maxima of order 5-6\%. A comparison of the monthly ERA temperature results of Figure S20 with the corresponding SBUV ozone results of Figure S19 shows that the high-latitude responses of both ozone and temperature occur in the summer hemisphere. They are therefore presumably a consequence of the enhanced photolytic and radiative effects of more continuous solar radiation at reduced solar-zenith angles in the polar regions during the summer season. Third, the amplitude $(\geq 1.5 \mathrm{~K})$ and is formally significant while the annually 
at comparable pressure levels, especially when the individual monthly responses are examined. Specifically, as seen in Figure 3a for the annually averaged SBUV monthly coefficients, marginally 945 significant ozone response maxima of order $3 \%$ are present in the985 responses in this location are significant during most months subtropical lower stratosphere near $50 \mathrm{hPa}$. These coefficients are formally significant with larger amplitudes (up to 8\%) during July and August (Figure S19). Similarly, the ERA Interim monthly efficients are formally significant with amplitudes $>0.5 \mathrm{~K}$ near $50 \mathrm{hPa}$ only during June, July, and August (Figure S20).

Comparing the annual temperature responses of Figure 5 with the corresponding model responses of Figure 2, it is first apparent that the three models in the top panel of Figure 2 yield statistically 13 significant minimum-to-maximum temperature changes in the 955 tropical upper stratosphere that are closer in magnitude $(>1 \mathrm{~K})$ to ${ }^{99}$ those obtained from the adjusted ERA data. This is further shown in Figure 6, which compares tropical averages of the ERA Interim temperature solar regression coefficients to similar averages of the model solar coefficients, analogous to the tropical ozone 960 comparison in Figure 4. None of the models, however, produce 500 secondary temperature response maxima at high polar latitudes (1) the hat are similar to those obtained in the ERA Interim data. The observationally estimated maxima are likely to be real because they are seen in both hemispheres in summer and correspond to 965 similar polar ozone maxima found in SBUV data. An examination Of Figures S13-S18 shows that most of the models (except GFDL-

M3) produce broad maxima in the temperature response at high summer latitudes near the stratopause but the amplitudes are in the range of 1.0-1.5 K, which is less than obtained from the reanalysis 970 data.

As discussed in section 2.5 in relation to Figures 2 and 6, many of the models produce broad positive responses in the tropicalb lower stratosphere that appear to be statistically significant but are probably influenced by aliasing from the effects of the El 975 Chichòn and Pinatubo volcanic aerosol injection events (and possibly ENSO events). In particular, CESM1-WACCM produces localized subtropical response maxima that are qualitativelyo15 the results are very similar to those obtained for 1979-2005 and similar to those obtained from the ERA Interim data. It is therefore entirely possible that some of the lower stratospheric thermal 980 response in the ERA Interim results is also influenced by volcanic aerosol and ENSO aliasing effects. However, the peak amplitudes in the lower stratosphere for CESM1-WACCM $(\sim 1 \mathrm{~K})$ are nearly a factor of two larger than those in Figure $5 \mathrm{~b}(\sim 0.6$ $\mathrm{K})$. Also, as seen in Figure S13, the monthly model temperature while, as seen in Figure S20, the corresponding observational monthly temperature responses near $50 \mathrm{hPa}$ are significant only during NH summer. Similarly, as seen in Figure S6, the CESM1WACCM 11-yr ozone response in the lower stratosphere is large 990 and significant during nearly all months while, as seen in Figure $50 \mathrm{hPa}$ is significant only during $\mathrm{NH}$ summer. Hence, the aliasing effects in the observations could be less than is the case for CESM1-WACCM. Consistent with this possibility, at least one 5 model, MIROC-ESM-CHEM, produces lower stratospheric 11yr ozone and temperature responses with amplitudes during the non-volcanic 1955-1981 period that are comparable to those during the volcanically-affected 1979-2005 period (Figures S30b and S31b). However, as already stated in section 2.5 above, without further information (e.g., investigation of the accuracies of different model sensitivities of lower stratospheric ozone and temperature to aerosol forcing), it is difficult to evaluate which model, CESM1-WACCM or MIROC-ESM-CHEM, is better able to simulate aliasing effects on observational solar regression 5 coefficients in the lower stratosphere.

\subsection{Zonal Wind}

The apparent offset errors found in ERA Interim temperature data in the upper stratosphere should be less problematic for the derived zonal wind field since the latter depends primarily on latitudinal temperature gradients, which are less sensitive to sudden steps in mean temperatures. The MLR model (1) was therefore applied to the ERA Interim zonal wind data over 19792012 to obtain the monthly solar regression coefficients plotted in Figure S21. Again, we consider the extended time period because the statistical significance is slightly increased. The regression coefficients are expressed as the change in the zonal wind in meters/second from solar minimum to maximum, as defined in section 2.5 . S19, the observationally estimated tropical ozone response near 
regression coefficients are only marginally significant during most months but are characterized by a consistent dependence on season in both hemispheres. Specifically, the largest zonal wind changes from solar minimum to maximum are estimated stratosphere during the winter season of each hemisphere. During orthern winter, the largest positive zonal wind response (up to $9 \mathrm{~m} / \mathrm{s}$ ) is obtained during November and December while, during southern winter, the largest positive response (up to 15 $\mathrm{m} / \mathrm{s}$ ) is obtained during July and August. During some of these months (December, July, and August), the positive zonal wind 1 esponse at subtropical to middle latitudes is complemented by weaker negative response at higher latitudes. In February, a large negative response (up to $-17 \mathrm{~m} / \mathrm{s}$ ) is obtained near the 1035 stratopause at $\sim 70^{\circ} \mathrm{N}$. As suggested for example by Gray et (2004) (see also Mitchell et al. 2014b), the latter negative response in late winter may reflect an increased tendency for major stratospheric warmings to occur later in the winter under solar maximum conditions when the polar vortex in early winter is 1040 stronger, on average, and less disturbed. These results are similar to those obtained previously by Frame and Gray (2010) using ERA 40 reanalysis data and operational analyses for the 19792008 period (see their Figure 7) and by Mitchell et al. (2014b) using nine different reanalysis datasets. The existence of 11 wintertime positive zonal wind anomalies in the midlatitude upper stratosphere was first reported based on rocketsonde data by Kodera and Yamazaki (1990). Later investigations of stratospheric data compiled by the former U.S. National Meteorological Center found evidence for a similar dynamical response in the southern 050 winter (Hood et al. 1993). The existence of a positive upper stratospheric zonal wind response to solar forcing during early winter is a basic element of the top-down mechanism for solar induced regional climate change (Kodera and Kuroda 2002; Matthes et al. 2006).

1055 Because the observationally estimated positive zonal wind response is a maximum during $\mathrm{NH}$ early winter (November andb95 calculated from the ensemble mean monthly temperature and December) and SH middle winter (July and August), Figure 7 shows the mean ozone, temperature, and zonal wind responses for these particular time periods. This figure is intended to illustrate the stratosphere during early to middle winter. The positive zonal wind responses in both hemispheres at these times are accompanied by strong negative latitudinal gradients in the ozone and temperature responses that are centered approximately on the 65 latitude of the zonal wind response.

\subsection{Seasonal Model Comparisons}

Finally, we wish to compare in more detail the seasonal ozone, temperature, and zonal wind responses obtained from the 6 high-top CMIP-5 models with interactive chemistry to 70 the observationally estimated responses of Figure 7 . The main objective is to determine whether the 3 models in the top panels of Figures 1, 2, 4, and 6 that produce substantial upper stratospheric ozone and temperature responses also produce a seasonally dependent response of ozone, temperature, and zonal 75 wind that compares favorably with observations. For this purpose, the monthly solar regression results for zonal wind for each of the 6 interactive models of Table 1 are plotted in Figures S22-S27.

Prior to considering the 6 interactive models of Table 1, it is useful to consider an ensemble of 3 simulations performed 80 by a high-top model without interactive chemistry (MIROCESM). This model is a version of MIROC-ESM-CHEM but without the interactive chemistry module. It differs from other high-top CMIP-5 models without interactive chemistry in that the ozone variation that was prescribed for this model did not 85 include a representation of the solar cycle (Watanabe et al. 2011). Like the other CMIP-5 models, this model did however impose a solar cycle variation of SSI (the NRL SSI). The model temperature and zonal wind responses therefore provide an interesting test of whether a realistic 11-yr ozone variation 90 in the upper stratosphere is important for producing a realistic thermal and dynamical response in winter. Figure 8 shows the ozone, temperature, and zonal wind changes from solar minimum to maximum during early northern winter and middle southern winter in the same format as Figure 7. (These averages were zonal wind solar regression coefficients plotted in Figures S28 and S29.) It is evident that this model produces no significant solar-induced latitudinal gradient in the temperature response 
and no corresponding positive zonal wind anomalies similar to 1100 those seen in Figure 7 even though a solar cycle SSI variation 40 model so there is no guarantee that the results are representative (but no accompanying ozone variation) was imposed. It is also interesting to note that there is no significant 11-yr response of lower stratospheric temperature in this model whereas there was at least a weak lower stratospheric 11-yr temperature response for 1105 the MIROC-ESM-CHEM model (Figure 2b).

Next, consider the 3 interactive models of Table 1 that did produce a substantial upper stratospheric ozone response and produced a relatively weak upper stratospheric temperature response (GFDL-CM3, GISS-E2-H, and GISS-E2-R). Averaging $\checkmark 1110$ together the ensemble and zonal mean ozone, temperature, an ${ }^{150}$ 1 zonal wind responses during November-December and JulyAdgust for these 3 models yields the mean responses shown in Figure 9. Again, no significant latitudinal temperature response gradients and no significant zonal wind anomalies are produced 1115 by these models. 1155 simulated by any of the 6 models examined here.

Next, consider the 3 interactive models of Table 1 that did produce a substantial upper stratospheric ozone and temperature response (CESM1-WACCM, MIROC-ESM-CHEM, and MRIESM1). Averaging together the ensemble and zonal mean ozone, 1120 temperature, and zonal wind responses during the same time periods for these 3 models yields the mean responses shown 60 in Figure 10. For these models, a mean negative latitudinal Ozone gradient is obtained centered on latitudes of $\sim 70^{\circ} \mathrm{N}$ in November-December and $70^{\circ} \mathrm{S}$ in July-August. Accompanying 1125 temperature gradients with zero lines centered on about $60^{\circ}$ in both hemispheres are obtained. Corresponding positive zonal 16 wind anomalies with amplitudes of $\sim 3 \mathrm{~m} / \mathrm{s}$ in NovemberDécember centered at $\sim 60^{\circ} \mathrm{N}$ and $\sim 8 \mathrm{~m} / \mathrm{s}$ in July-August centered near $45^{\circ} \mathrm{S}$ are obtained, although only the southern 1130 hemisphere one is marginally significant. The structure of the southern hemisphere wind signal is similar to that estimate $4_{40}$ from observations in that a weaker negative wind anomaly is present at higher latitudes. However, the mean amplitudes in both hemispheres are weaker by at least a factor of two than those 1135 estimated from the ERA Interim data in Figure 7.

Lastly, Figure 11 shows a similar plot for the interactive model175 that produced the strongest and most significant 11-yr response of upper stratospheric ozone, the MRI-ESM1 model (Figures 1c of those for an ensemble mean. Nevertheless, we show them to illustrate that a larger response in the northern hemisphere is possible in at least some simulations. As seen in the figure, the upper stratospheric zonal wind anomaly is marginally significant 5 with an amplitude of $\sim 6 \mathrm{~m} / \mathrm{s}$ and is centered near $50^{\circ} \mathrm{N}$ close to

the stratopause. For comparison, the corresponding observational zonal wind anomaly has an amplitude of $\sim 7 \mathrm{~m} / \mathrm{s}$ and is centered near $30^{\circ} \mathrm{N}$ (Figure $5 \mathrm{c}$ ). The model positive zonal wind anomaly in the southern hemisphere in July-August is formally significant with a peak amplitude of $8 \mathrm{~m} / \mathrm{s}$ near $2 \mathrm{hPa}$, which compares to a marginally significant anomaly derived from the ERA data with a peak amplitude of $\sim 13 \mathrm{~m} / \mathrm{s}$ near the stratopause.

However, it should be noted that the large negative zonal wind response found in reanalysis data in February (section 3.3) is not

\section{Summary and Discussion}

A prerequisite for a successful model simulation of the topdown component of solar-induced climate change is that the model should produce an upper stratospheric response of ozone, temperature, and zonal wind to 11-yr solar forcing that agrees at least to first order with available observations (Kodera and Kuroda 2002; Matthes et al. 2006; Yukimoto and Kodera 2007; Hood et al. 2013). Since continuous global satellite measurements of stratospheric ozone and temperature began in 1979 and since the CMIP-5 model simulations cover the period up to 2005 , this study has focused on the 1979-2005 period for detailed comparisons of solar signals in CMIP-5 models with available observations. Only the 6 models with high tops and interactive ozone chemistry were considered (Table 1). The Mg II solar UV index, derived 70 from satellite SSI data, was adopted as the solar predictor or basis function in the MLR analysis (rather than TSI as done in Paper 1) because it is available for this particular time period and produces larger and more statistically significant solar regression coefficients in stratospheric ozone data (e.g., Figure S12).

In section 2.5, it was found that three of the six models (CESM1-WACCM, MIROC-ESM-CHEM, and MRIESM1) produce substantial solar-induced responses of ozone 
and temperature in the upper stratosphere (Figures 1 and 2).

This result was based on MLR analyses over 1979-2005 of 4 1180 ensemble members for CESM1-WACCM, 1 member each for MIROC-ESM-CHEM and MRI-ESM1, and 5 members each fonz20 probably influenced by aliasing from the El Chichòn and Pinatubo GFDL-CM3, GISS-E2-H, and GISS-E2-R. As found in sections 3.1 and 3.2, the observationally estimated annually averaged monthly ozone and temperature solar regression coefficients for period after 1979 (Figures 3 to 6) compare favorably with the corresponding coefficients for CESM1-WACCM, MIROC-ESM1-225 CHEM, and MRI-ESM1 in the upper stratosphere, especially when uncertainties in the observational estimates are taken into account. The remaining three models (GFDL-CM3, GISS-E2-H, and GISS-E2-R) yield much weaker upper stratospheric responses thât are difficult to reconcile with available observations230 However, the latter three models do, in effect, provide a valuable baseline or set of control runs against which results for the three models with a substantial upper stratospheric response can be 1195 compared.

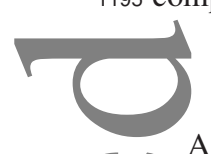

As discussed in section 2.2, there are some significant differences in the radiation and photolysis codes for the six models that could potentially explain why only three of the models produce substantial 11-yr upper stratospheric ozone variations that rree with observational estimates. In the case of the GFDL-2 CM3 model, which produced the weakest 11-yr ozone variation thost altitudes in the stratosphere, the applied photolysis rate calculation scheme appears to have been designed mainly for tropospheric applications and could therefore have omitted $\mathrm{O}_{2}$ 1205 photolysis. In the case of the two GISS-E2 models, the weak245 of MIROC-ESM-CHEM with no interactive chemistry and no 11-yr upper stratospheric ozone variation could potentially be caused by omissions of $\mathrm{O}_{2}$ absorption in the radiation code and the SRB contribution to $\mathrm{O}_{2}$ dissociation in the photolysis rate code. The three models with substantial upper stratospheric 1210 ozone variations have fewer issues overall, although WACCM alsø250 was imposed in the model. This shows that such a model with no omits the contribution of $\mathrm{O}_{2}$ absorption in the $\mathrm{UV}$ to radiative heating below $65 \mathrm{~km}$ and MIROC-ESM-CHEM omits water vapor photolysis. These deficiencies could potentially lead to some slight overestimation of the upper stratospheric ozone response.
As also discussed extensively in sections 2.6 and 3.2, the 11-yr response of lower stratospheric ozone and temperature extracted by MLR in many of the 6 models considered here is volcanic aerosol injection events (see also Chiodo et al. 2014). However, the extent of the aliasing appears to vary from model to model with results for some models (e.g., CESM1-WACCM) being strongly affected while those for others (e.g., MIROCESM-CHEM) are not very affected. Thus, the extent to which observational estimates of the lower stratospheric response (which unfortunately are only available after 1979) are also affected by such aliasing is difficult to quantify based on the model simulations examined here. At least one model (MIROC-ESM-

CHEM) simulates an 11-yr ozone and temperature response in the lower stratosphere during a period (1955-1981) when there were no major volcanic aerosol injection events.

As found in section 3.3, in agreement with previous studies, the observationally estimated zonal wind response to 11-yr solar 235 forcing, although only marginally significant, has a maximum positive amplitude during $\mathrm{NH}$ early winter (November and December) and during SH middle winter (July and August). These zonal wind anomalies are accompanied by negative latitudinal gradients in the ozone and temperature responses during the same months in both winter hemispheres (Figure 7). Therefore, in section 3.4, a more detailed comparison of the ozone, temperature, and zonal wind responses from the 6 selected high-top models with the observationally estimated responses was carried out. It was first found (Figure 8) that three simulations using a version representation of the solar cycle in its prescribed ozone variation produce no significant negative latitudinal temperature gradients or positive zonal wind anomalies in either winter hemisphere, even though a solar cycle variation of SSI (the NRL SSI model) significant 11-yr stratospheric ozone variation and a conservative SSI variation is not able to produce a realistic upper stratospheric seasonal response. The three interactive chemistry models that did not produce a significant annually averaged response of upper stratospheric ozone and only a weak temperature response also yielded no significant seasonal response in either hemisphere 
(Figure 9). The three interactive models that did produce annually averaged ozone and upper stratospheric responses agreeing to first order with observational constraints yielded a stronger combined 1260 upper stratospheric seasonal response in both hemispheres,300 especially in the southern hemisphere in July and August (Figure 10). The multi-model mean zonal wind response for these three models in November and December has an amplitude of only $\mathrm{m} / \mathrm{s}$ and is not statistically significant. But some simulations using these three models do produce a relatively strong zonal305 wind response during northern early winter that is consistent with observational estimates. In particular, the single MRI-ESM1 mpdel simulation produces a mean zonal wind anomaly of $\sim$ $\mathrm{m} / \mathrm{s}$ during November and December (Figure 11). Several of CESM1-WACCM simulations also produced a large positive $\varphi_{310}$ wind anomaly during this season, although the ensemble mean amplitude was much weaker. Further simulations using the MRIE\$M1 model are needed to test whether the stronger northern winter zonal wind anomalies are a robust feature of this model for a conservative SSI variation.

The model ozone and temperature response gradients and the

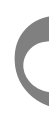
corresponding zonal wind anomalies of Figures 10 and 11 occur at somewhat higher latitudes than those that are estimated from observations (Figure 7). This difference has also been noted 1280 previously by Kodera et al. (2003) and may be related to an overalli22 A tendency for general circulation models to simulate a polar night jet that is centered at a somewhat higher latitude than is observed. Kodera et al. (2003) have also argued that the inability of GCMs to produce an amplitude of the solar-induced polar night jet 1285 oscillation that is as large as estimated from observations is related 32 to a failure to realistically produce interannual variability in the polar night jet amplitude. The treatments of dynamical processes for the six models considered here, including gravity wave parameterizations which are important for accurately simulating 1290 upper stratospheric winds, are described in detail in the reference $3^{33}$ listed in Table 1. None of the models have obvious deficiencies in this regard. However, the weaker and equatorward-shifted polar night jets for the two GISS models (section 2.3 and Figures S4S5) could reflect an increased influence of small-scale gravity 1295 waves on the circulation for this model. Their structure is similarr335 to that obtained for polar night jets in the UIUC model when overly strong gravity wave drag was applied (see Figure 5 of Yang et al. 2000). The weaker amplitudes could also be related to the relatively low tops of the two GISS models ( $\sim 66 \mathrm{~km}$; Table 1). Finally, the overestimation of the SH polar night jet amplitude by CESM1-WACCM (section 2.3 and Figure S5) is likely related to a known SH cold pole bias for this model. The latter suggests a need for adjustments in the treatments of either planetary wave forcing or gravity waves. Possible approaches are currently being 5 investigated by the WACCM team.

The negative latitudinal ozone response gradients in the winter high-latitude upper stratosphere that are found in both observations (Figure 7) and model simulations (e.g., Figures $10,11, \mathrm{~S} 2 \mathrm{k})$ are too strong to be due to the decrease with increasing latitude of the solar UV-induced ozone production rate. Instead, they are probably dynamical in origin since they are associated with positive zonal wind anomalies. It is unlikely that direct dynamical transport of ozone itself plays a role because the ozone chemical lifetime in the upper stratosphere 1315 is much shorter than dynamical timescales. Rather it is more likely that ozone is responding photochemically to dynamically induced changes in temperature and/or other minor species concentrations that affect the ozone balance. The temperature changes seen in both observations and models have the same sign as the ozone changes, which is inconsistent with temperature feedback effects on ozone photochemistry (temperature increases alone result in ozone decreases, and vice versa in the upper stratosphere). Therefore, dynamically induced changes in minor species concentrations that are important for ozone catalytic 25 losses may be implicated. For example, odd nitrogen has a photochemical lifetime near the stratopause $(\sim 1$ month) that is much longer than dynamical timescales (e.g., Brasseur and Solomon 2005). Hence, a transport-induced increase in the latitudinal gradient of odd nitrogen in the upper stratosphere under solar maximum conditions would contribute to the negative latitudinal gradient in the ozone response for both models and observations. More detailed diagnostic analyses of the CMIP5 models by the individual modeling groups is needed to test whether this process or others are involved.

Regardless of the exact origin of the negative latitudinal ozone response gradients, it is clear that they would assist in 
amplifying the zonal wind response. A strong negative latitudinal ozone gradient will radiatively enhance the negative latitudinal temperature gradient, which, by thermal wind balance, would 1340 amplify the zonal wind anomaly. This could therefore represent a positive feedback mechanism for producing a stronger upper stratospheric dynamical response than expected for models that ${ }_{380}$ impose a conservative 11-yr SSI variation. In any case, although further work is needed to assess models with prescribed ozone, the results of this analysis show that high-top models with interactive Ozone chemistry that simulate substantial responses of ozone and emperature in the upper stratosphere are capable of producing strong upper stratospheric dynamical response. Such a dynamical response can, in turn, lead to significant troposphere-ocean signals in'coupled models via the top-down mechanism (e.g., Yukimoto and Kodera 2007).

\section{Acknowledgements}

The work reported here was directly motivated by the SPARC SOLARIS-HEPPA SolarMIP project. The authors thank 1355 all CMIP-5 modeling groups responsible for producing the mulations summarized in Table 1 and for providing their modek 39 data to the CMIP-5 archive. Special thanks to Makato Deushi and Kiyotaka Shibata for clarifying the nature of the chemistry ompdnent of the MRI-ESM1 model and to Dan Marsh for helpful 1360 comments about the WACCM model. Comments and criticisms by the reviewers are also appreciated. Work at the University400 of Arizona was supported by grant 1251092 from the U.S. National Science Foundation and by grant NNX14AD44G from NASA Living With a Star program. Work at the University 1365 of Thessaloniki was supported by European Cooperation in Science and Technology (COST) Action ES1005 (Towards McLandress et al. (2014).

mpre complete assessment of the impact of solar variability on the Earth's Climate - TOSCA). Work at the University of Oxford was supported by the U.K. Natural Environment 1370 Research Council as well as by TOSCA. Work at the World Radiation Center was supported by the Swiss National Science 106 Foundation under grant CRSII2-147659 (FUPSOL II) and by the State Secretariat for Education, Research and Innovation of the Swiss Confederation under grant C11.01124 (SOVAC). Work at 1375 the GEOMAR Helmholtz Centre for Ocean Research in Kiel,
Germany is partly supported within the Helmholtz-University Young Investigators Group NATHAN funded by the Helmholtz Association through the President's Initiative and Networking Fund and by the GEOMAR.

\section{Appendix}

In this appendix, evidence for artificial offsets (step changes) in zonally averaged ERA Interim temperature data in the upper stratosphere (5 $\mathrm{hPa}$ and above) is discussed and an empirical procedure is applied to adjust the data to minimize the offsets. The data were obtained at levels ranging from 1000 to $1 \mathrm{hPa}$ (the highest level available for public access) from the European Centre for Medium-Range Weather Forecasts (http://apps.ecmwf.int/datasets).

The top panel of Figure A1 compares deseasonalized anomalies (deviations from the long-term monthly means) of ERA Interim 1390 temperature data at the highest available level $(1 \mathrm{hPa})$ averaged over low latitudes $\left(35^{\circ} \mathrm{S}\right.$ to $\left.35^{\circ} \mathrm{N}\right)$ to the $\mathrm{Mg}$ II solar UV index over the 1979-2012 period. Large offsets occur at several points in the time series that apparently are related to major changes in satellite instrumentation and/or changes in the reanalysis procedure. The largest single offset between July and August of 1998 closely follows the launch of the first Advanced Microwave Sounding Unit (AMSU) on the NOAA 15 satellite in May of that year. The AMSU was an improvement over the Microwave Sounding Unit (MSU), which began observations together with the SSU on TIROS-N in 1978. Other smaller offsets appear to occur between June and July of 1979 and between February and April of 1985. Offset errors of this type are clearly found in the data only at the 1,2 , and $5 \mathrm{hPa}$ levels. For further discussion of these offset errors in the ERA Interim data and methods for minimizing them, see

In order to estimate the magnitude of offset errors such as those in the top panel of Figure A1, a simple average of the low-latitude temperature anomalies was calculated in a 12-month window on either side of the offsets (except for the 1979 offset for which only 6 months were available to calculate the first average). The offset errors estimated from the differences between these two averages are: 1 hPa: 1979: -4.33 K; 1985: -1.87 K; 1998: +4.94 K; 2 hPa: 1979: -3.16 K; 1985: -1.38 K; 1998: +2.25 K; 5 hPa: 1998: -2.14

K. Assuming that the offset errors estimated at low latitudes apply 
1415 approximately to all latitudes, an adjusted monthly ERA Interim data set was constructed in which these estimated errors were minimized. The bottom panel of Figure A1 compares low-latitude455 temperature anomalies calculated from the adjusted data at $1 \mathrm{hPa}$ to the Mg II UV index. As can be seen, the adjusted anomalies at 1420 this level exhibit a quasi-decadal variation that is roughly in phase with the solar cycle.

To test to what extent the offset errors may influence solar temperature regression coefficients derived from the ERA Interim data, the MLR model (1) was applied separately to the unadjusted and adjusted data. It was found that the overall spatial structure of the solar regression coefficients was surprisingly similar for $(3)$ the two data sets, apparently due to the ability of the MLR method to identify solar-correlated decadal variations between the offset locations. However, the amplitudes of the solar temperature 1430 regression coefficients near the stratopause are increased by about $50 \%$ when using the unadjusted data set rather than the adjusted data set. Most of this increase is due to the fact that the large positive offset error in 1998 near $1 \mathrm{hPa}$ occurs during a rising phase of the solar cycle as seen in the top panel of Figure A1. 1435 Hence, the adjusted data provide a better estimate for the true amplitude of the solar-induced temperature response near the stratopause.

\section{References}

Adachi Y, Yukimoto S, Deushi M, Obata A, Nakano H, Tanaka T, Hosaka M, Sakami T, Yoshimura H, Hirabara M et al. 2013. Basic performance of a new Earth system model of the Meteorological Research Institute (MRIESM1). Papers in Meteorology and Geophysics 64: 1-19, ${ }_{1480}$ doi:310.2467/mripapers.64.1.

1445 Anderson J, Balaji V, Broccoli J, Cooke WF, Delworth TL, Dixon K, Donner L, Dunne K, Freidenreich SM, Garner S et al. 2004. The new GFDL global atmosphere and land model AM2-LM2: Evaluation with prescribed SST simulations 485 Journal of Climate 17: 4641-4673.

1450 Austin J, Tourpali K, Rozanov E, Akiyoshi H, Bekki S, Bodeker G, Brühl C, Butchart N, Chipperfield M, Deushi M et al. 2008. Coupled chemistry climate model simulations of the solar cycle in ozone and temperature. Journal of Geophysical Research Atmospheres 113: D11306, doi:10.1029/2007JD009391.

Bian H, Prather M. 2002. Fast-J2: Accurate simulations of photolysis in global climate models. Journal of Atmospheric Chemistry 41: 281-296.

Brasseur GP, Solomon S. 2005. Aeronomy of the Middle Atmosphere. Springer.

Briegleb B. 1992. Delta-Eddington approximation for solar radiation in the NCAR Community Climate Model. Journal of Geophysical Research Atmospheres 97: 7603-7612.

Briegleb B, Light B. 2007. A Delta-Eddington multiple scattering parameterization for solar radiation in the sea ice component of the Community Climate System Model. NCAR Technical Note TN-472+STR, National Center for Atmospheric Research, Boulder, Colorado, USA.

Chabrillat S, Kockarts G. 1997. Simple parameterization of the absorption of the Lyman-alpha line. Geophysical Research Letters 24: 2659-2662.

Chiodo G, Marsh DR, Garcia-Herrera R, Calvo N, Garcia JA. 2014. On the detection of the solar signal in the tropical stratosphere. Atmospheric Chemistry and Physics 14: 52515269.

Chipperfield MP. 1999. Multiannual simulations with a threedimensional chemical transport model. J. Geophys. Res. 104: $1781-1805$.

Chipperfield MP. 2006. New version of the TOMCAT/SLIMCAT offline chemical transport model: Intercomparison of stratospheric tracer experiments. Quarterly Journal of the Royal Meteorological Society 132: 1179-1203.

Cionni I, Eyring V, Lamarque JF, Randel WJ, Stevenson DS, Wu F, Bodeker GE, Shepherd TG, Shindell DT, Waugh DW. 2011. Ozone database in support of CMIP5 simulations: Results and corresponding radiative forcing. Atmospheric Chemistry and Physics 11: 11267-11292.

Cochrane D, Orcutt DH. 1949. Application of least squares regression to relationships containing autocorrelated error 
terms. Journal of the American Statistical Association. 44: 32-61.

Crooks SA, Gray LJ. 2005. Characterization of the 11-Year solar signal using a multiple regression analysis of the ERA-4 $4_{530}$ dataset. Journal of Climate 18: 996-1015.

1495 Dee DP, Uppala SM, Simmons AJ, Berrisford P, Poli P, Kobayashi S, Andrae U, Balmaseda MA, Balsamo G, Bauer P, et al. 2011. The ERA-Interim reanalysis: Configuration and performance of the data assimilation system. Quarterly Journal of the Royal Meteorological Society 137: 553-597. ${ }^{1535}$

1500 Deushi M, Shibata K. 2011. Development of an MRI ChemistryClimate Model ver. 2 for the study of tropospheric and stratospheric chemistry. Papers in Meteorology and Geophysics 62: 1-46.

Dhomse S., Chipperfield MP, Feng W, Haigh JD. 2011. Solar 1505 response in tropical stratospheric ozone: a 3-D chemical transport model study using ERA reanalyses. Atmospheric Chemistry and Physics 11: 12773-12786.

Donner LJ, Wyman BL, Hemler RS, Horowitz LW, Ming Y, () Zhao M, Golaz J-C, Ginoux P, Lin S-J, Schwarzkopf MD et al. 2011. The dynamical core, physical parameterizations, and basic simulation characteristics of the atmospheric component AM3 of the GFDL global coupled model CM3.

Journal of Climate 24: 3484-3519.

Ermolli I, Matthes K, Dudok de Wit T, Krivova NA, Tourpali $K_{1550}$ Weber M, Unruh YC, Gray LJ, Langematz U, Pilewskie P et al. 2013, Recent variability of the solar spectral irradiance and its impact on climate modeling. Atmospheric Chemistry and Physics 13: 3945-3977.

Eyring V, Arblaster J, Cionni I, Sedlácek J, Perlwitz J, Young PJ, Bekki S, Bergmann D, Cameron-Smith P, Collins WJ et al. 2013. Long-term ozone changes and associated climate impacts in CMIP5 simulations. Journal of Geophysical Research Atmospheres 118: 5029-5060, doi:10.1002/jgrd.50316.

1525 Fioletov VE. 2009. Estimating the 27-day and 11-yeans60 solar cycle variations in tropical upper stratospheric ozone. Journal of Geophysical Research 114: D02302, doi:10.1029/2008JD010499.

Fortuin JPF, Kelder H. 1998. An ozone climatology based on ozonesonde and satellite measurements. Journal of Geophysical Research 103: 31709-31734.

Frame THA, Gray LJ. 2010. The 11-yr solar cycle in ERA-40 data: An update to 2008. Journal of Climate 23: 2213-2222.

Friedenreich S, Ramaswamy V. 1999. A new multiple-band solar radiative parameterization for general circulation models. Journal of Geophysical Research Atmospheres 104: 3138931409 .

Garny H, Bodeker GE, Dameris M. 2007. Trends and variability in stratospheric mixing: 1979-2005. Atmospheric Chemistry and Physics. 7: 5611-5624.

Gray LJ, Beer J, Geller M, Haigh J, Lockwood M, Matthes K, Cubasch U, Fleitmann D, Harrison G, Hood L et al. 2010. Solar influences on climate. Reviews of Geophysics 48 : RG4001, doi:10.1029/2009RG000282.

Gray LJ, Crooks S, Pascoe C, Sparrow S, Palmer M, Solar and QBO influences on the timing of stratospheric sudden warmings, J. Atmos. Sci., 61(23), 2777-2796, 2004.

Gray LJ, Rumbold ST, Shine KP. 2009. Stratospheric temperature and radiative forcing response to 11-year solar cycle changes in irradiance and ozone. Journal of the Atmospheric Sciences 66: $2402-2417$.

Gray LJ, Scaife AA, Mitchell DM, Osprey S, Ineson S, Hardiman S, Butchart N, Knight J, Sutton R, Kodera K, 2013. A lagged response to the 11 year solar cycle in observed winter Atlantic/European weather patterns. Journal of Geophysical Research: Atmospheres 118: 13405-13420.

Haigh JD. 1994. The role of stratospheric ozone in modulating the solar radiative forcing of climate. Nature 370: 544-546.

Haigh JD. 2003. The effects of solar variability on the Earth's climate. Philosophical Transactions: Mathematical, Physical and Engineering Sciences 361: 95-111. 
Harder JW, Fontenla JM, Pilewski P, Richard EC, Woods TN. 2009. Trends in solar spectral irradiance variability in the visible and infrared. Geophysical Research Letters 36:600 L07801, doi:10.1029/2008GL036797.

Heath D, Schlesinger B. 1986. The $\mathrm{Mg} 280 \mathrm{~nm}$ doublet as a monitor of changes in solar ultraviolet irradiance. Journal of Geophysical Research 91: 8672-8682.

Hood LL. 1986. Coupled stratospheric ozone and temperature responses to short-term changes in solar ultraviolet flux: An analysis of Nimbus 7 SBUV and SAMS data. Journal of Geophysical Research 91: 5264-5276.

Hood LL, Huang Z, Bougher SW. 1991. Mesospheric effects ${ }_{1610}$ of solar ultraviolet variations: Further analysis of SME IR ozone and Nimbus 7 SAMS temperature data. Journal of Geophysical Research 96: 12989-13002.

Hood LL, Jirikowic J, McCormack JP, 1993. Quasi-decadal variability of the stratosphere: Influence of long-term solar ultraviolet variations. Journal of the Atmospheric Sciences 50: 3941-3958.

Hood LL, Soukharev BE, McCormack JP. 2010. Decadal variability of the tropical stratosphere: Secondary influence of the El Niño-Southern Oscillation. Journal of Geophysical Research Atmospheres 115: D11113, doi:10.1029/2009JD012291.

1585 Hood LL, Soukharev BE. 2012. The lower-stratospheric response to 11-yr solar forcing: Coupling to the troposphere-ocean response. Journal of the Atmospheric Sciences 69: 18411864.

Hood LL, Schimanke S, Spangehl T, Bal S, Cubasch U. 2013. 1590 The surface climate response to 11-yr solar forcing during northern winter: Observational analyses and comparisons with GCM simulations. Journal of Climate 26: 7489-7506.

Huang $\mathrm{T}$, Walters $\mathrm{S}$, Brasseur $\mathrm{G}$, Hauglustaine $\mathrm{D}$, Wu $\mathrm{W}^{1630}$ Chabrillat S, Xuexi T, Granier C, Smith A, Kockarts G. 1998. Description of SOCRATES- a chemical dynamical radiative two-dimensional model. NCAR Technical Note NCAR/TN440+EDD, doi:10.5065/D6K0726C.
Keating GM, Nicholson III JY, Young DF, Brasseur G, De Rudder A. 1987. Response of middle atmosphere to shortterm solar ultraviolet variations, 1, Observations. Journal of Geophysical Research 92: 889-902.

Kodera K, Kuroda Y. 2002. Dynamical response to the solar cycle: Winter stratopause and lower stratosphere. Journal of Geophysical Research: Atmospheres 107: 4749, doi:10.1029/2002JD002224.

Kodera K, Matthes K, Shibata K, Langematz U, Kuroda Y. 2003. Solar impact on the lower mesospheric subtropical jet: A comparative study with general circulation model simulations. Geophysical Research Letters 30: 1315, doi:10.1029/2002GL016124.

Kodera K, Yamazaki K. 1990. Long-term variation of upper stratospheric circulation in the Northern Hemisphere in December. Journal of the Meteorological Society of Japan 68: $101-105$.

5 Kopp G, Rottman G, Rottman G. 2005. The total irradiance monitor (tim): science results: In: The Solar Radiation and Climate Experiment (SORCE), Springer, pp. 129-139.

Koppers G, Murtagh D. 1996. Model studies of the influence of $\mathrm{O}_{2}$ photodissociation parameterisation in the SchumannRunge bands on ozone related photolysis in the upper atmosphere. Annales Geophysicae 14: 68-79.

Kramarova NA, Frith SM, Bhartia PK, McPeters RD, Taylor SL, Fisher BL, Labow GJ, DeLand MT. 2013. Validation of ozone monthly zonal mean profiles obtained from the version 8.6 Solar Backscatter Ultraviolet algorithm. Atmospheric Chemistry and Physics 13: 6887-6905.

Kyrölä E, Laine M, Sofieva V, Tamminen J, Pälvärinta S-M, Tukiainen S, Zawodny J, Thomason L. 2013. Combined SAGE II - GOMOS ozone profile data set 1984-2011 and trend analysis of the vertical distribution of ozone. Atmospheric Chemistry and Physics 13: 10645-10658.

Lacis A, Hansen J. 1974. A parameterization for the absorption of solar radiation in the Earth's atmosphere. Journal of the Atmospheric Sciences 31: 118-133. 
1635 Lean J. 2000. A decadal solar effect in the evolution of the Sun's spectral irradiance since the Maunder Minimum. Geophysical Research Letters 27: 2425-2428, doi:10.1029/2000GL000043.

Lean J, DeLand M. 2012. How does the Sun's spectrum vary? Journal of Climate 25, 2555-2560.

Lean J, Beer J, Bradley R. 1995. Reconstruction of solar irradiance since 1610: Implications for climate change. Geophysical Research Letters 22: 3195-3198,680 doi:10.1029/2005GL025342.

F645 Lee H, Smith AK. 2003. Simulation of the combined effects ( ) of solar cycle, quasi-biennial oscillation, and volcanic forcing on stratospheric ozone changes in recent decades. Journal of Geophysical Research: Atmospheres 108: 4049 , doi:10.1029/2001JD001503.

1650 Madronich S, Flocke S. 1998. The role of solar radiation in atmospheric chemistry. In: Handbook of Environmental Chemistry, P. Boule, ed., Springer-Verlag, 1-26. use in nudged chemistry-climate model simulations. Atmospheric Chemistry and Physics 14: 1547-1555.

McPeters RD, Bhartia PK, Haffner D, Labow GJ, Flynn L. 2013. The v8.6 SBUV ozone data record: An overview. Journal of Geophysical Research: Atmospheres

118: doi:10.1002/jgrd.50597.

Meehl GA, Arblaster JM, Matthes K, Sassi F, van Loon H. 2009. Amplifying the Pacific climate system response to a small 11-year solar cycle forcing. Science 325: 1114-1118.

Minschwaner K, Siskind D. 1993. A new calculation of nitric oxide photolysis in the stratosphere, mesosphere, and lower thermosphere. Journal of Geophysical Research Atmospheres 98: 20401-20412.

1685 Mitchell DM, Misios S, Gray LJ, Tourpali K, Matthes K, Hood L, Schmidt H, Chiodo G, Thiéblemont R, Rozanov E, Krivolutsky A. 2014a. Solar signals in CMIP-5 simulations: The stratospheric pathway. Quarterly Journal of the Royal Meteorological Society in press.

A Marsh DR, Garcia RR, Kinnison DE, Boville BA, Sassi F,̧9o Mitchell DM, Gray LJ, Fujiwara M, Hibino T, Anstey JA, Solomon SC, Matthes K. 2007. Modeling the whole atmosphere response to solar cycle changes in radiative and geomagnetic forcing. Journal of Geophysical Research: Atmospheres 112: D23306, doi:10.1029/2006JD008306.
Ebisuzaki W, Harada Y, Long C, Misios S, Stott P, Tan D. 2014b. Signatures of naturally induced variability in the atmosphere using multiple reanalysis datasets. Quarterly Journal of the Royal Meteorological Society in press.

Marsh DR, Mills MJ, Kinnison DE, LaMarque J-F, Calvos95 Randel WJ, Wu F. 2007. A stratospheric ozone profile data set for

N, Polvani L. 2013. Climate change from 1850 to 2005 simulated in CESM1(WACCM). Journal of Climate 26: $7372-7391$

Matthes K, Kuroda Y, Kodera K, Langematz U. 2006. Transfer of the solar signal from the stratosphere to the troposphere.700 Northern winter. Journal of Geophysical Research: Atmo1665 spheres 111: D06108, doi:10.1029/2005JD006283.

McCormick MP, Zawodny J, Veiga R, Larsen J, Wang PH. 1989. An overview of SAGE I and II ozone measurements. Planetary and Space Science 37: 1567-1586.

McLandress C, Plummer DA, Shepherd TG. 2014. Technical Note: A simple procedure for removing temporal discontinuities in ERA-Interim upper stratospheric temperatures for 1979-2005: Variability, trends, and comparisons with column ozone data. Journal of Geophysical Research: Atmospheres 112: D06313, doi:10.1029/2006JD007339.

Remsberg EE. 2008. On the response of Halogen Occultation Experiment (HALOE) stratospheric ozone and temperature to the 11-year solar cycle forcing. Journal of Geophysical Research 113:D22304, doi:10.1029/2008JD010189.

Remsberg EE. 2014. Decadal-scale responses in middle and upper stratospheric ozone from SAGE II version 7 data. Atmospheric Chemistry and Physics 14: 1039-1053.

Russell GL, Miller JR, Rind D. 1995. A coupled atmosphereocean model for transient climate change studies. Atmosphere-Ocean 33: 683-730. 
Sato M, Hansen J, McCormick J, Pollack J. 1993. Stratospheric aerosol optical depths, 1850-1990. Journal of Geophysical Research 98(D12): 22987-22994.

Scaife AA, Ineson S, Knight JR, Gray LJ, Kodera K, Smith DM. 2013. A mechanism for lagged North Atlantic climate response to solar variability. Geophysical Research Letters 40: 434-439, doi:10.1002/grl.50099.

Schmidt GA, Kelley M, Nazarenko L, Ruedy R, Russell GL, Aleinov, Bauer M, Bauer SE, Bhat MK, Bleck R, et al. 2014. Configuration and assessment of the GISS ModelE $2^{755}$ contributions to the CMIP5 archive. Journal of Advances in Modeling Earth Systems 6: 141-184.

Sekiguchi M, Nakajima T. 2008. A k-distribution based radiation code and its computational optimization for an atmospheric general circulation model. Journal $a f_{760}$ Quantitative Spectroscopy and Radiative Transfer 109:

1725 2779-2793.

hapiro AV, Rozanov EV, Shapiro AI, Egorova TA, Harder J, Weber M, Smith AK, Schmutz W, Peter T. 2013. The role of the solar irradiance variability in the evolution of the middle atmosphere during 2004-2009. Journal 465 Taylor KE, Stouffer RJ, Meehl GA. 2012. An overview of CMIPof Geophysical Research Atmospheres 118: 3781-3793, dbi:10.1002/jgrd.50208.

K, Deushi M, Sekiyama TT, Yoshimura H. 2005. Development of an MRI chemical transport model for the study of stratospheric chemistry. Papers in Geophysics and Meteorology 55: 75-119.

Shindell DT, Pechony O, Voulgarakis Z, Faluvegi G, Nazarenko L, Lamarque J-F, Bowman K, Milly G, Kovari B, Ruedy R, Schmidt GA. 2013. Interactive ozone and methane chemistry in GISS-E2 historical and future climate simulations. Atmospheric Chemistry and Physics 13: 2653-2689.

Solomon S, Portmann RW, Garcia RR, Thomason LW, Poole LR, McCormick MP. 1996. The role of aerosol variations in anthropogenic ozone depletion at northern midlatitudes. Journal of Geophysical Research: Atmospheres 101: 6713-
Soukharev BE, Hood L. 2006. Solar cycle variation of stratospheric ozone: Multiple regression analysis of longterm satellite data sets and comparisons with models. Journal of Geophysical Research: Atmospheres 111: D20314, doi:10.1029/2006JD007107.

SPARC-CCMVal 2010. SPARC Report on the Evaluation of Chemistry-Climate Models, in SPARC Report No. 5, WCRP132, WMO/TD-No. 1526, edited by V. Eyring, T. G. Shepherd, and D. W. Waugh, Univ. of Toronto, Toronto, Ont., Canada. Available at http://www.sparc-climate.org/ publications /sparc-reports/ sparc-report-no5.

Sukhodolov T, Rozanov E, Shapiro AI, Anet J, Cagnazzo C, Peter T, Schmutz W. 2014. Evaluation of the ECHAM family radiation codes performance in the representation of the solar signal. Geoscientific Model Development Discussions 7: $1337-1356$.

Sun S, Bleck R. 2006. Multi-century simulations with the coupled GISS-HYCOM climate model: Control experiments. Climate Dynamics 26: 407-428.

5 and the experiment design. Bulletin of the American Meteorological Society 93: 485-498.

Thompson DWJ, Wallace JM. 1998. The Arctic Oscillation signature in the wintertime geopotential height and temperature fields. Geophysical Research Letters 25: 12971300.

Tiao G, Reinsel G, Xu D, Pedrick J, Zhu X, Miller A, DeLuisi J, Mateer C, Wuebbles D. 1990. Effects of autocorrelation and temporal sampling schemes on estimates of trend and spatial correlation. Journal of Geophysical Research: Atmospheres 95: 20507-20517.

Viereck R, Puga L. 1999. The NOAA MG II core-to-wing solar index: Construction of a 20-year time series of chromospheric variability from multiple satellites. Journal of Geophysical Research: Atmospheres 104: 9995-10005. 
Wang YM, Lean J, Sheeley Jr N. 2005. Modeling the sun's magnetic field and irradiance since 1713. The Astrophysicals20 Journal 625: 522-538.

Watanabe S, Hajima T, Sudo K, Nagashima T, Takemura T, Okajima H, Nozawa T, Kawase H, Abe M, Yokohata T, et al. 2011. MIROC-ESM 2010: Model description and basic results of CMIP5-20c3m experiments. Geoscientific Model ${ }^{1825}$ Development 4: 845-872.

Woods TN. 2012. Solar irradiance variability: Comparisons of 1790 observations over solar cycles 21-24. In: EGU General - Assembly Conference Abstracts, edited by Abbasi A, Giesen N. 14: 1520. of Ozone Depletion: 2006. World Meteorological Organiza-
tion, Global Ozone Research and Monitoring Project, Report
No. 50.

Yang F, Schlesinger ME, Rozanov E. 2000. Description and performance of the UIUC 24-layer stratosphere/troposphere general circulation model. Journal of Geophysical Research 105: 17925-17954.

( ) 1840 Yukimoto S, Kodera K. 2007. Annular modes forced from the stratosphere and interactions with the oceans. Journal of the Meteorological Society of Japan 85: 943-952.

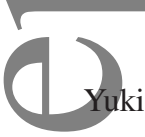
kimoto S, Yoshimura H, Hosaka M, Sakami T, Tsujino H, Hirabara M, Takana TY, Deushi M, Obata A, Nakan甲845 H, et al. 2011. Meteorological Research Institute-Earth System Model Version 1 (MRI-ESM1) - Model Description. Technical Reports of the Meteorological Research Institute No. 64, Meteorological Research Institute, Tsukuba City, Japan.

Yukimoto S, Adachi Y, Hosaka M, Sakami T, Youshimura H, Hirabara M, Tanaka T, Shindo S, Tsujino H, Deushi M et al. 2012. A new global climate model of the Meteorological Research Institute: MRI-CGCM3 Model description and basic performance. Journal of the Meteorological Society of Japan 90A: 23-64, doi:10.2151/jmsj.2012-A02. 


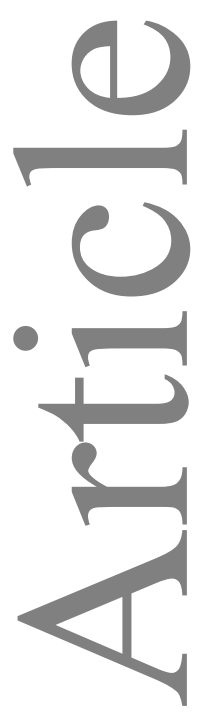

Table 1: High-Top CMIP-5 Models With Interactive Chemistry

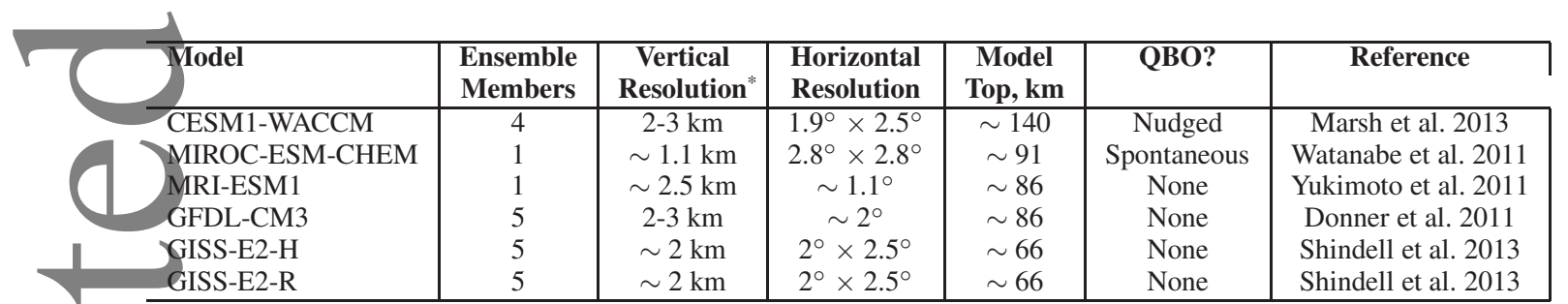

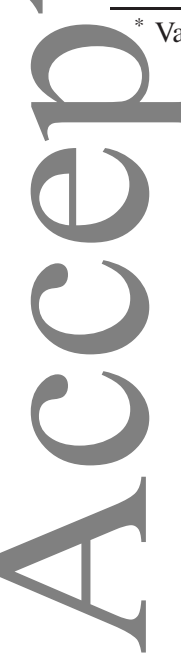




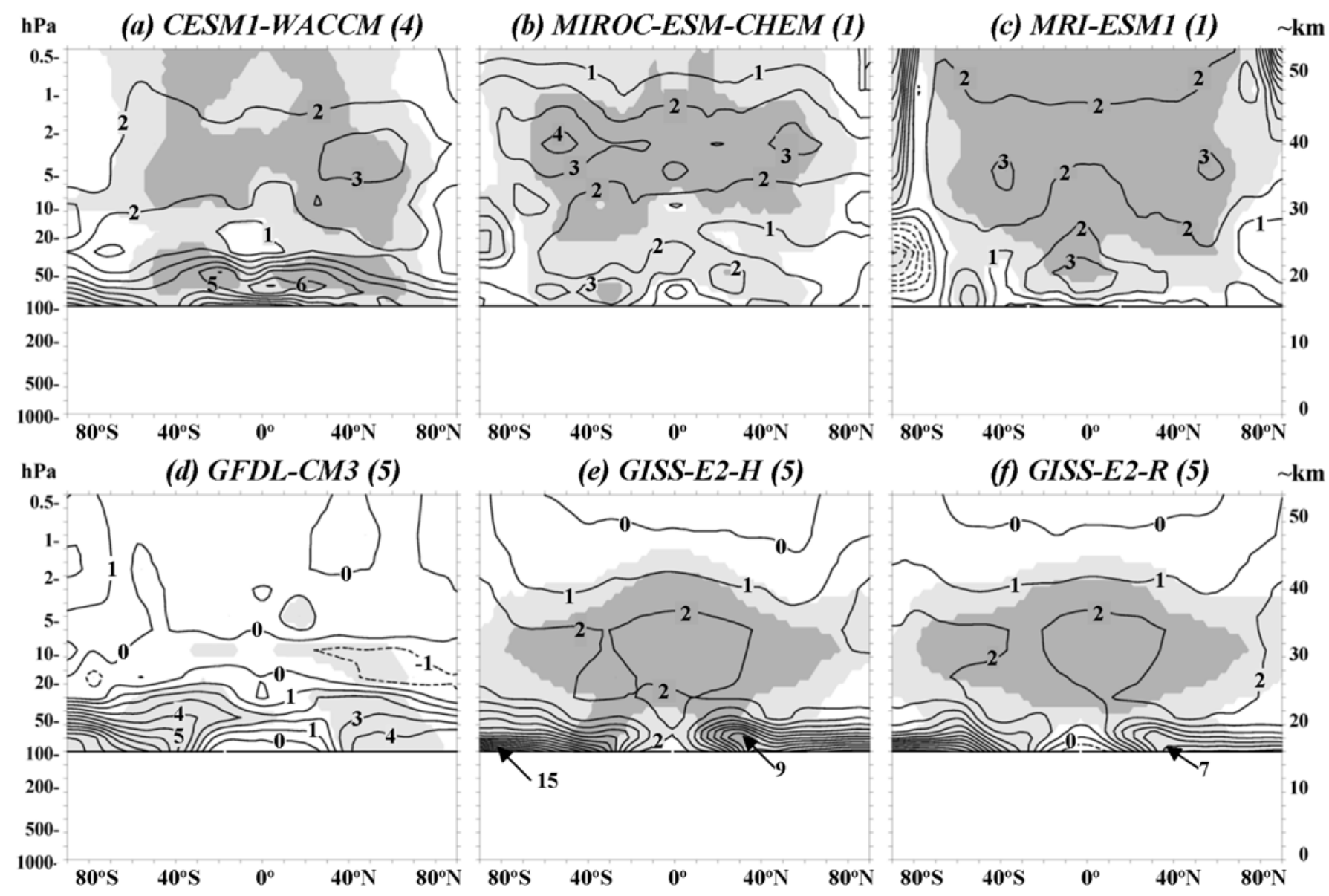

Figure 1. Annual and zonal mean ozone per cent change (max - min) over the 1979-2005 period for the 6 high-top models with interactive chemistry (see the text). Dark (light) shading indicates statistical significance at the 2 (1) sigma level. The contour interval is $1 \%$. 


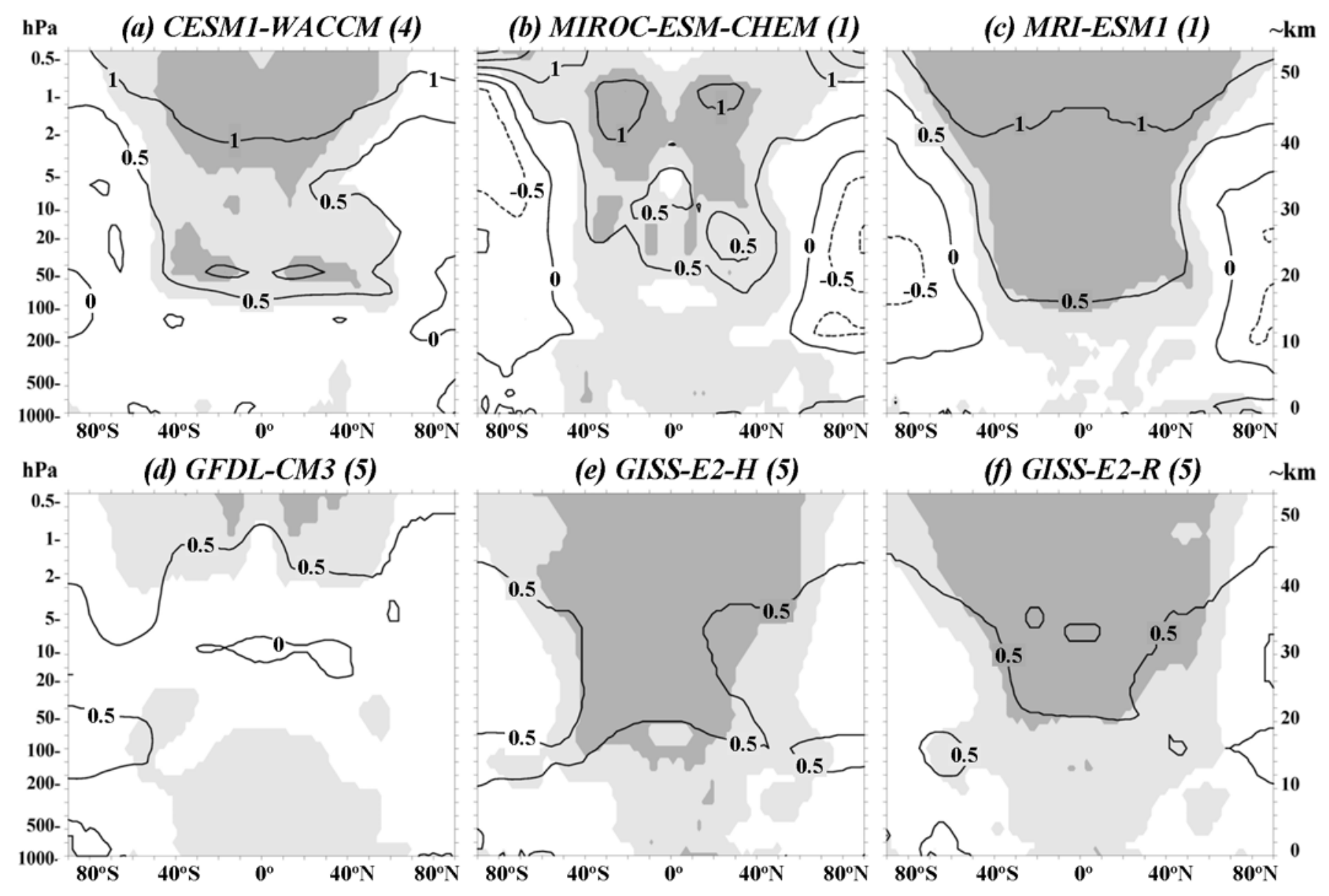

Figure 2. Same format as Figure 1 but for the annual and zonal mean temperature change (max - min) over the 1979-2005 period. 


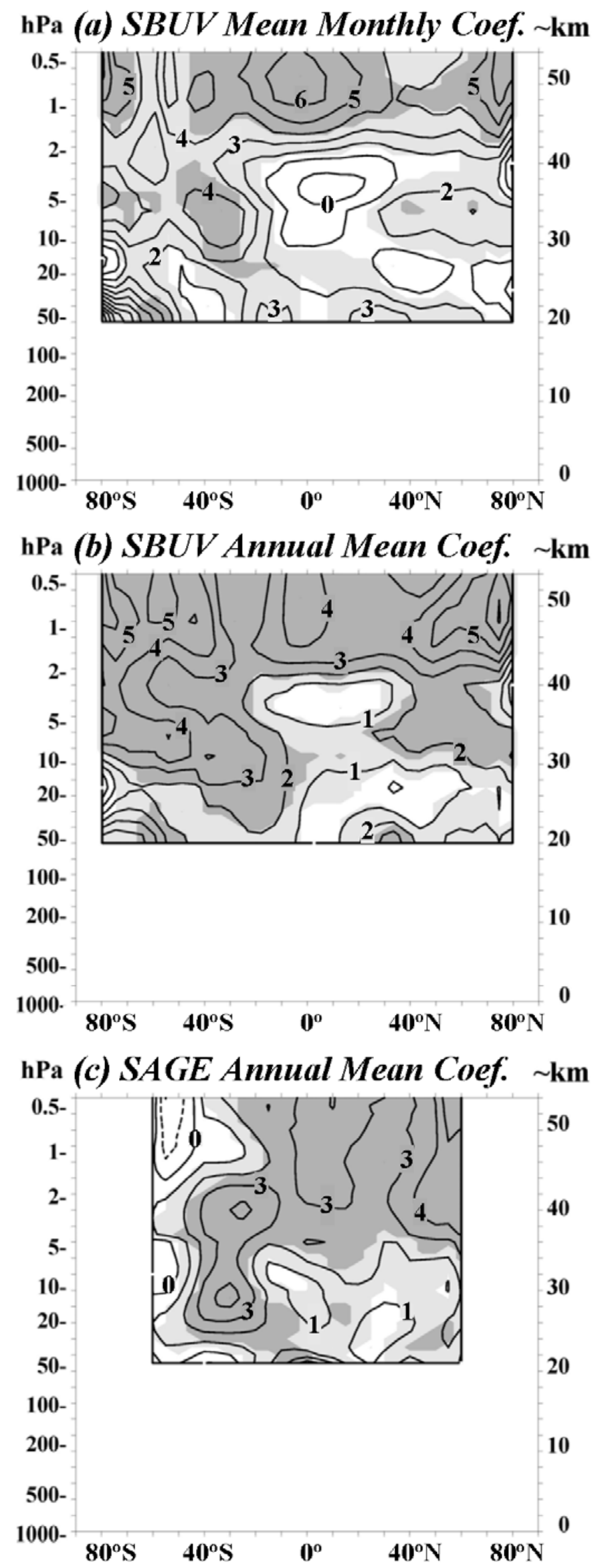

Figure 3. (a) Annually averaged monthly ozone change (max - min) for the Version 8 merged SBUV ozone data over the 1979-2003 period; (b) Same as (a) but for the annual mean ozone change; (c ) Annual mean ozone change for the Version 6 SAGE II data set over the 1985-2005 period. 

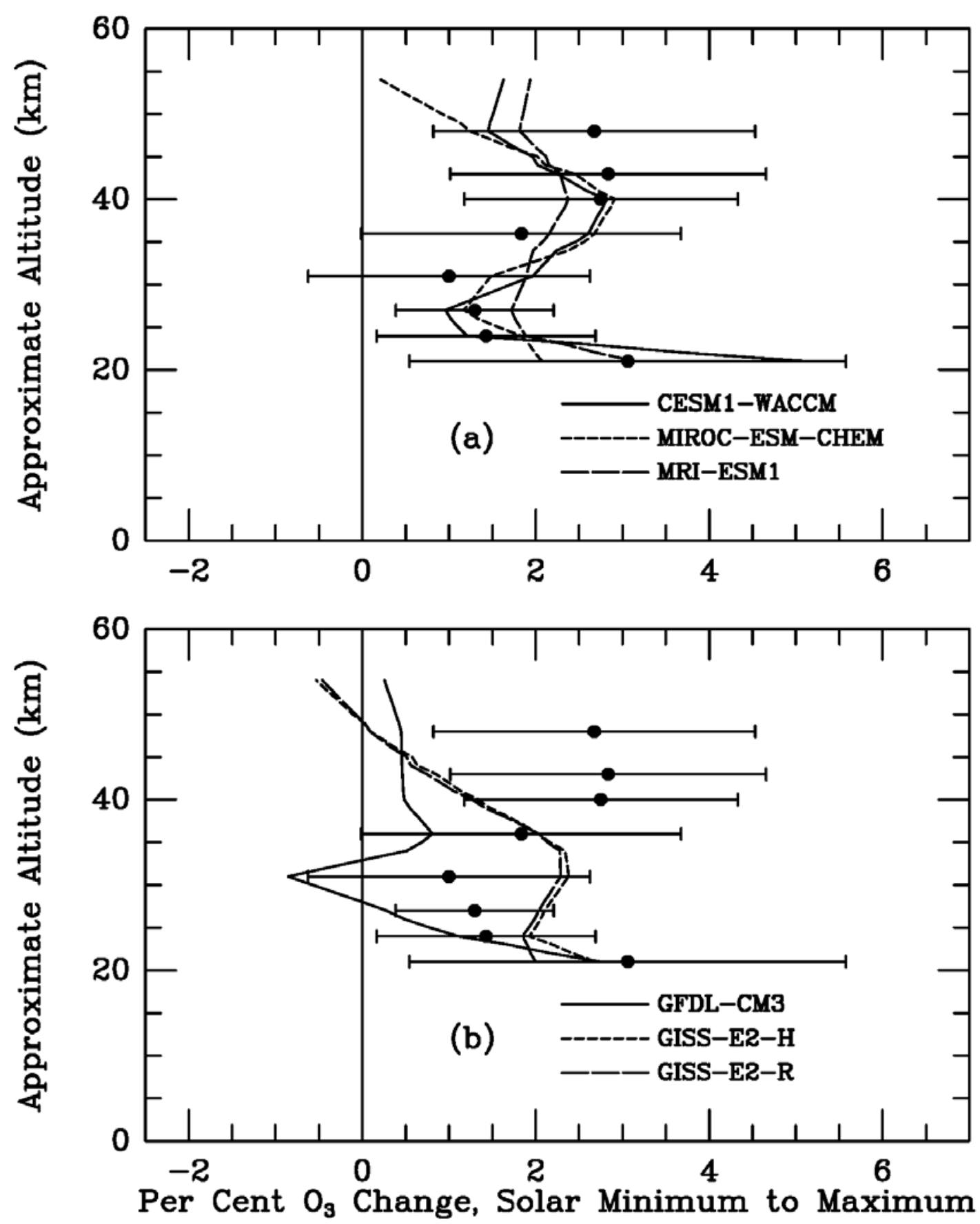

Figure 4. Comparison of tropical $\left(25^{\circ} \mathrm{S}\right.$ to $\left.25^{\circ} \mathrm{N}\right)$ averages of SAGE II annual mean ozone solar regression coefficients (solid circles with $2 \sigma$ error bars) with similar averages of the annually averaged model solar regression results of Figure 1. The top panel (a) is for the three models with a substantial upper stratospheric ozone response while the bottom panel (b) is for the remaining three models. 


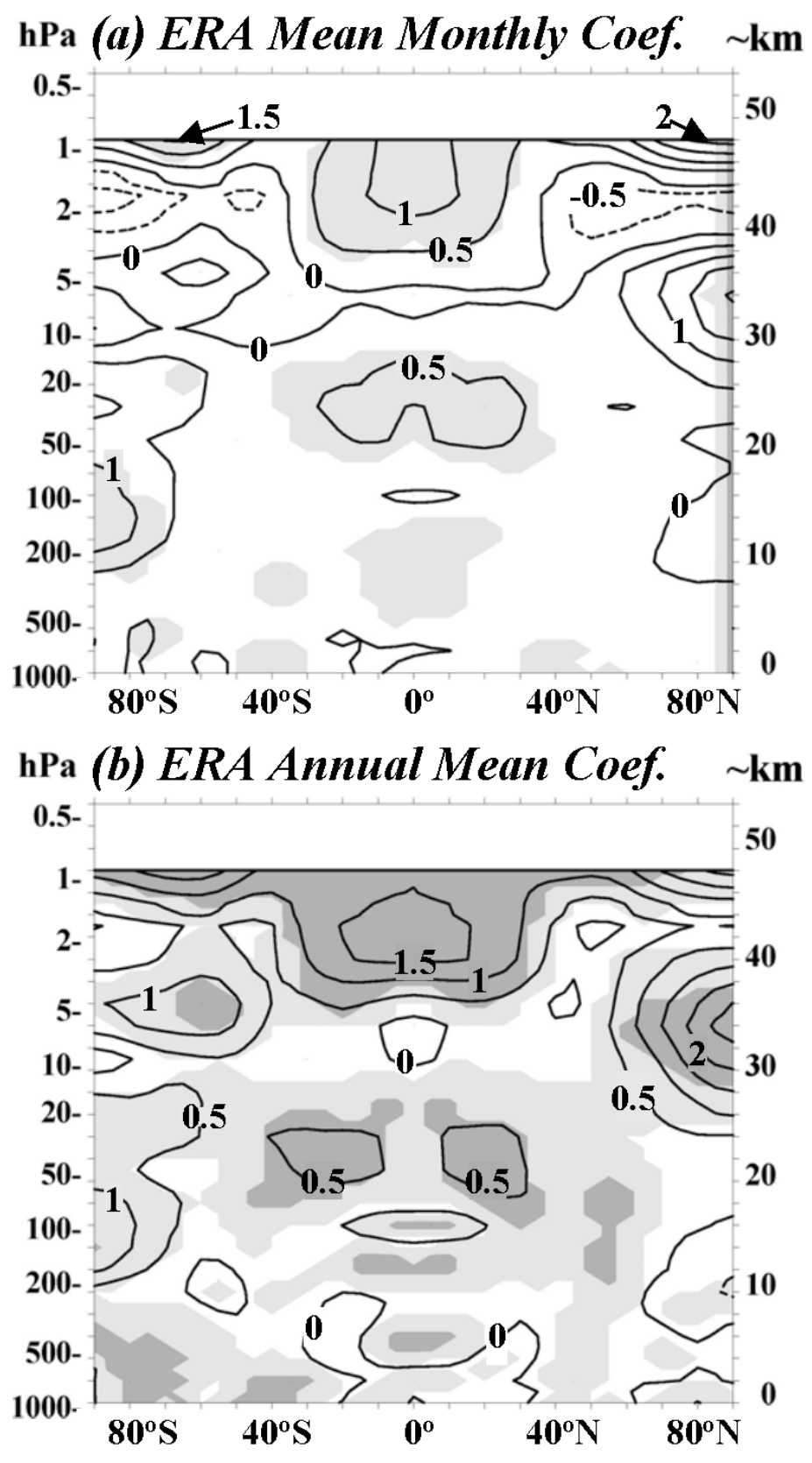

Figure 5. (a) Annually averaged monthly temperature change (max - min) over the 19792012 period for the ERA Interim reanalysis data set after adjustments for offset step changes in the upper stratosphere; (b) Same as (a) but for the annual mean temperature change with each monthly temperature anomaly considered as an independent data point. 

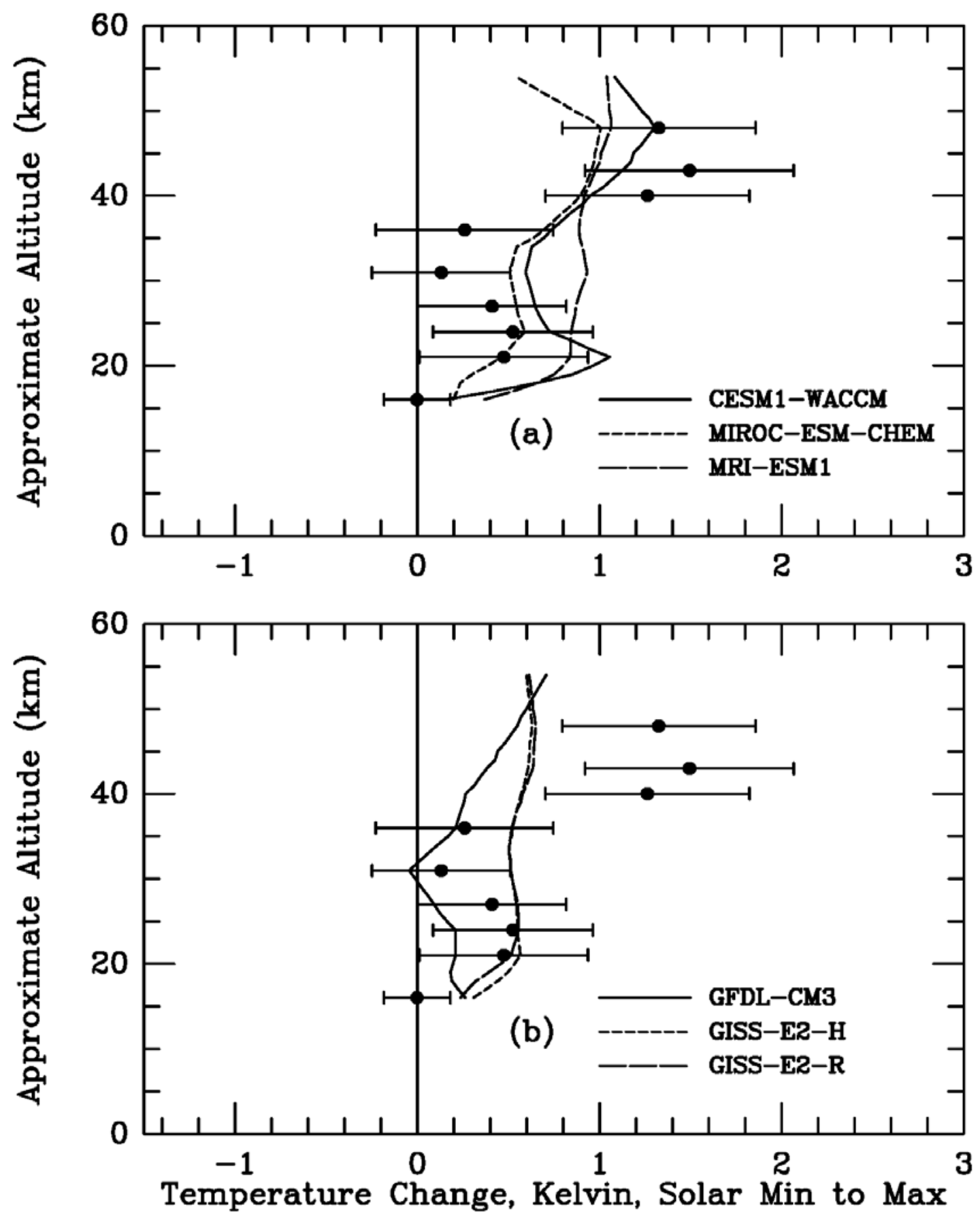

Figure 6. Comparison of tropical $\left(25^{\circ} \mathrm{S}\right.$ to $\left.25^{\circ} \mathrm{N}\right)$ averages of adjusted ERA Interim annual mean temperature solar regression coefficients (solid circles with $2 \sigma$ error bars) with similar averages of the annually averaged model solar regression results of Figure 2. The top panel (a) is for the three models with a substantial upper stratospheric ozone response while the bottom panel (b) is for the remaining three models. 


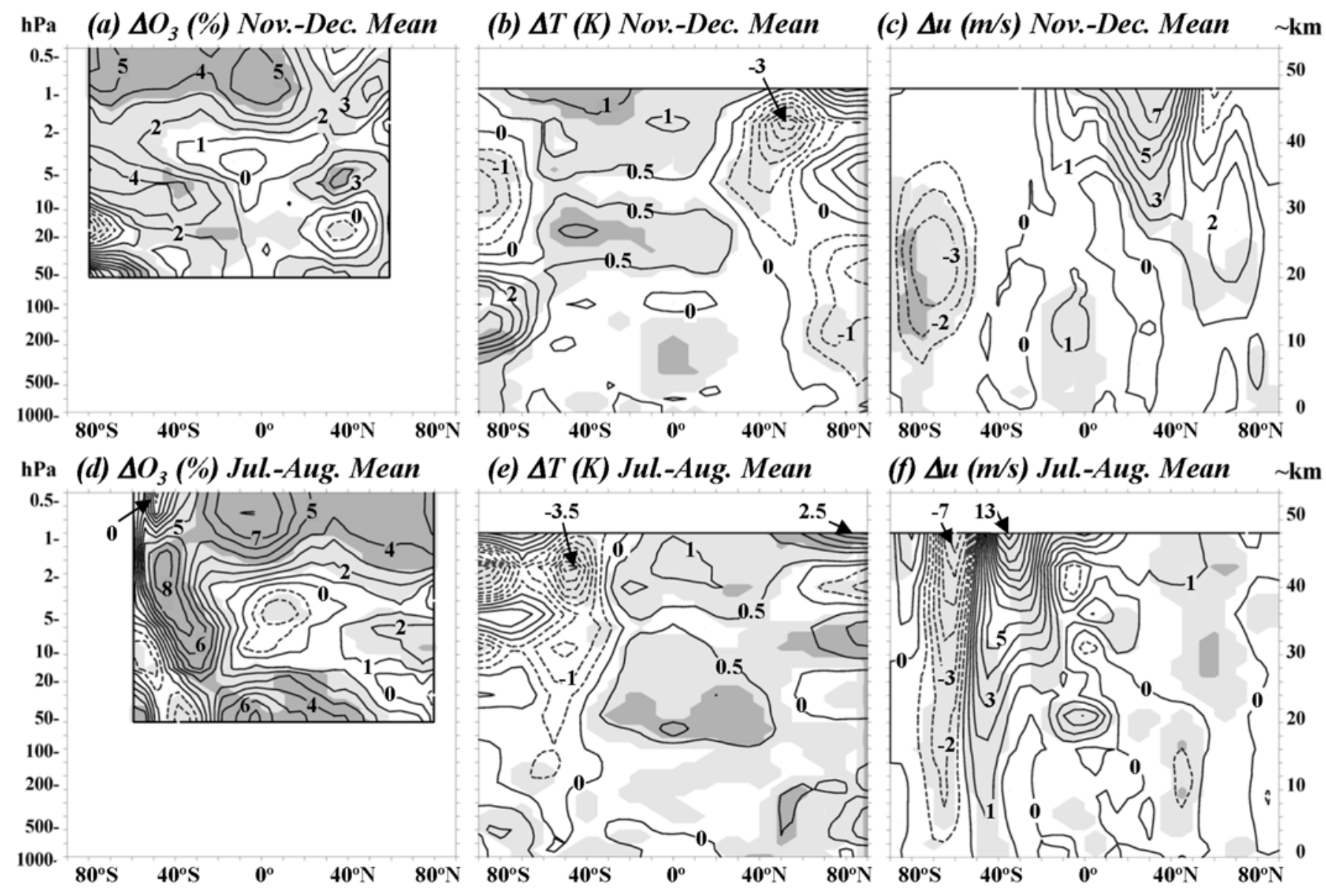

Figure 7. Observationally estimated solar cycle change ( $\max$ - min) in zonal mean ozone, temperature, and zonal wind during early northern winter (top panel) and middle southern winter (bottom panel). See the text. The contour interval is $1 \%$ for ozone, $0.5 \mathrm{~K}$ for temperature, and $1 \mathrm{~m} / \mathrm{s}$ for zonal wind. 


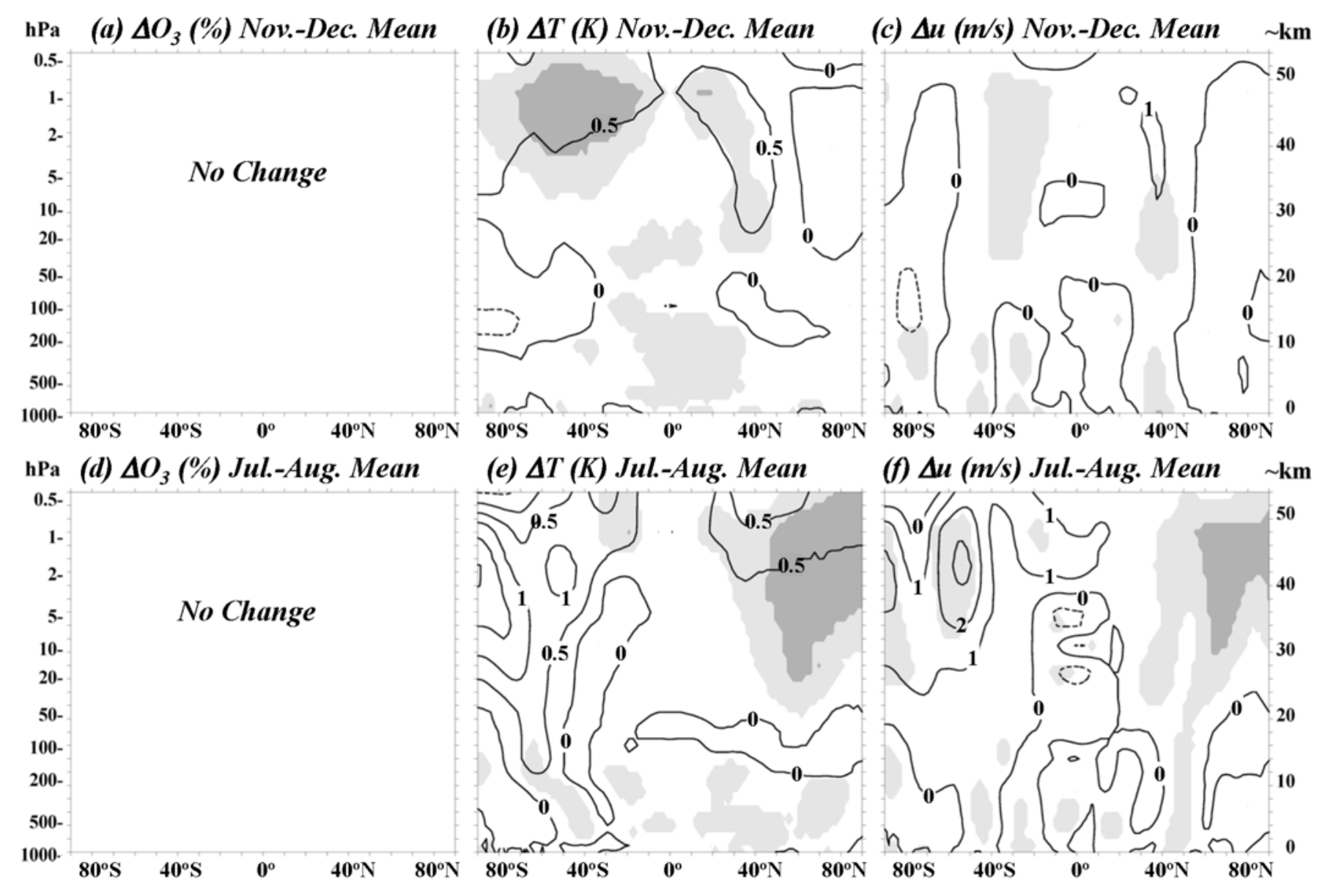

Figure 8. Solar cycle change ( $\max -\min )$ in zonal mean temperature and zonal wind during early northern winter (top panel) and middle southern winter (bottom panel) for the MIROCESM model (mean of 3 ensemble members) over the 1979-2005 period. This model used a prescribed ozone database that did not include a representation of the solar cycle. The contour interval is $0.5 \mathrm{~K}$ for temperature, and $1 \mathrm{~m} / \mathrm{s}$ for zonal wind. 


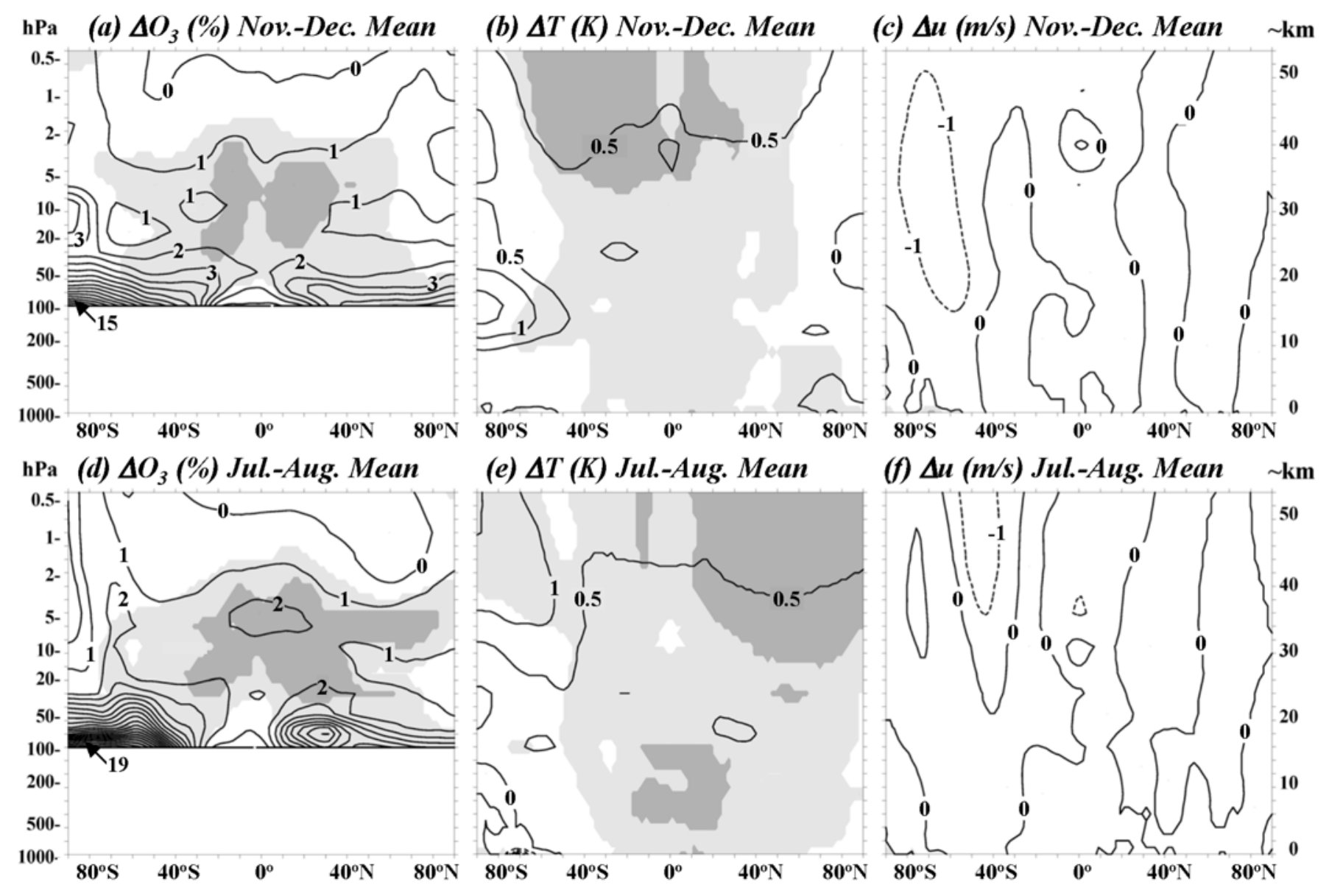

Figure 9. Mean solar cycle change ( $\max$ - $\min$ ) in zonal mean ozone, temperature, and zonal wind during early northern winter (top panel) and middle southern winter (bottom panel) for the three interactive chemistry models with relatively weak upper stratospheric ozone responses (GFDL-CM3, GISS-E2-H, and GISS-E2-R.). The contour interval is $1 \%$ for ozone, $0.5 \mathrm{~K}$ for temperature, and $1 \mathrm{~m} / \mathrm{s}$ for zonal wind. 


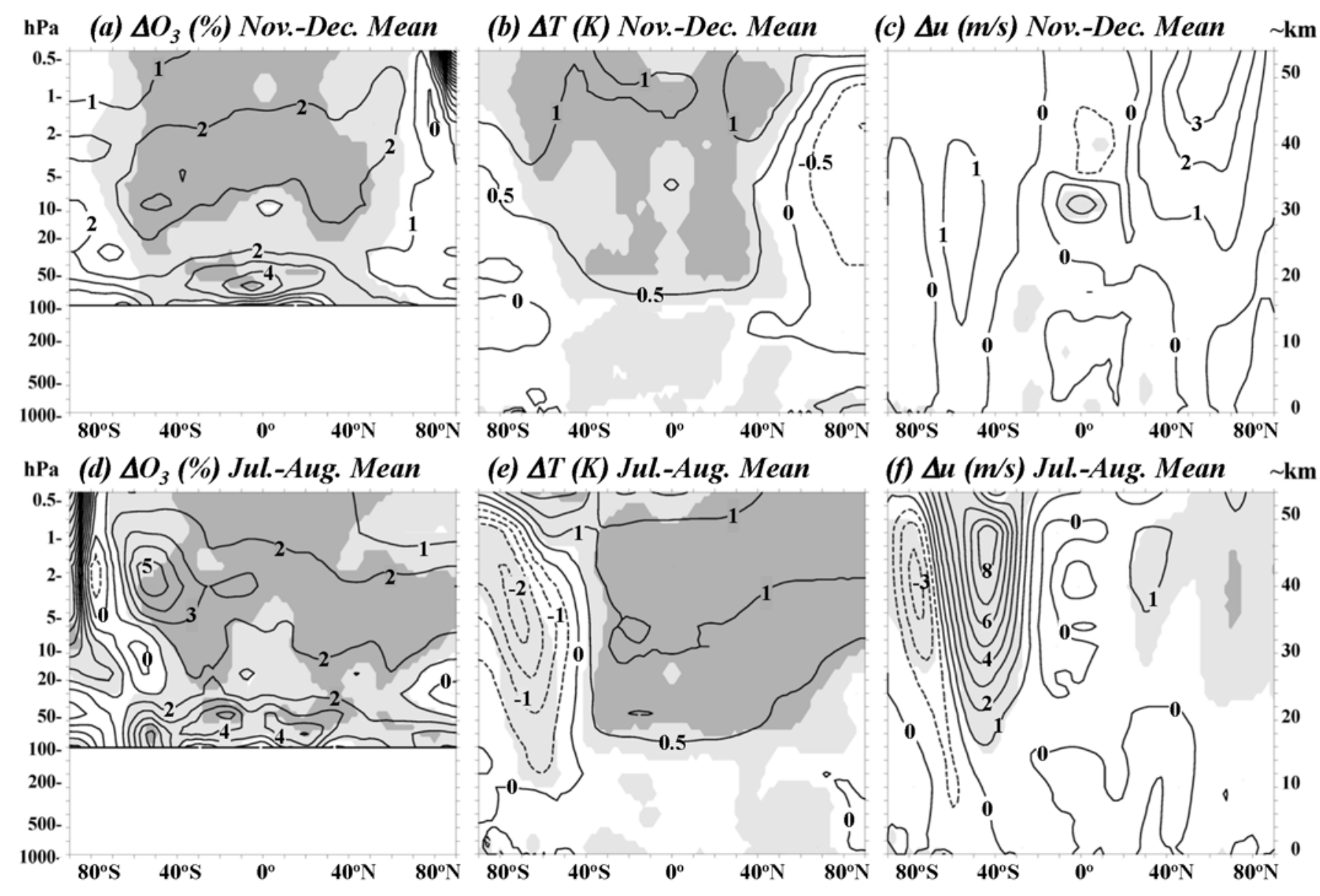

Figure 10. As in Figure 9 but for the three interactive chemistry models with relatively strong upper stratospheric ozone responses (CESM1-WACCM, MIROC-ESM-CHEM, and MRI-ESM1). 


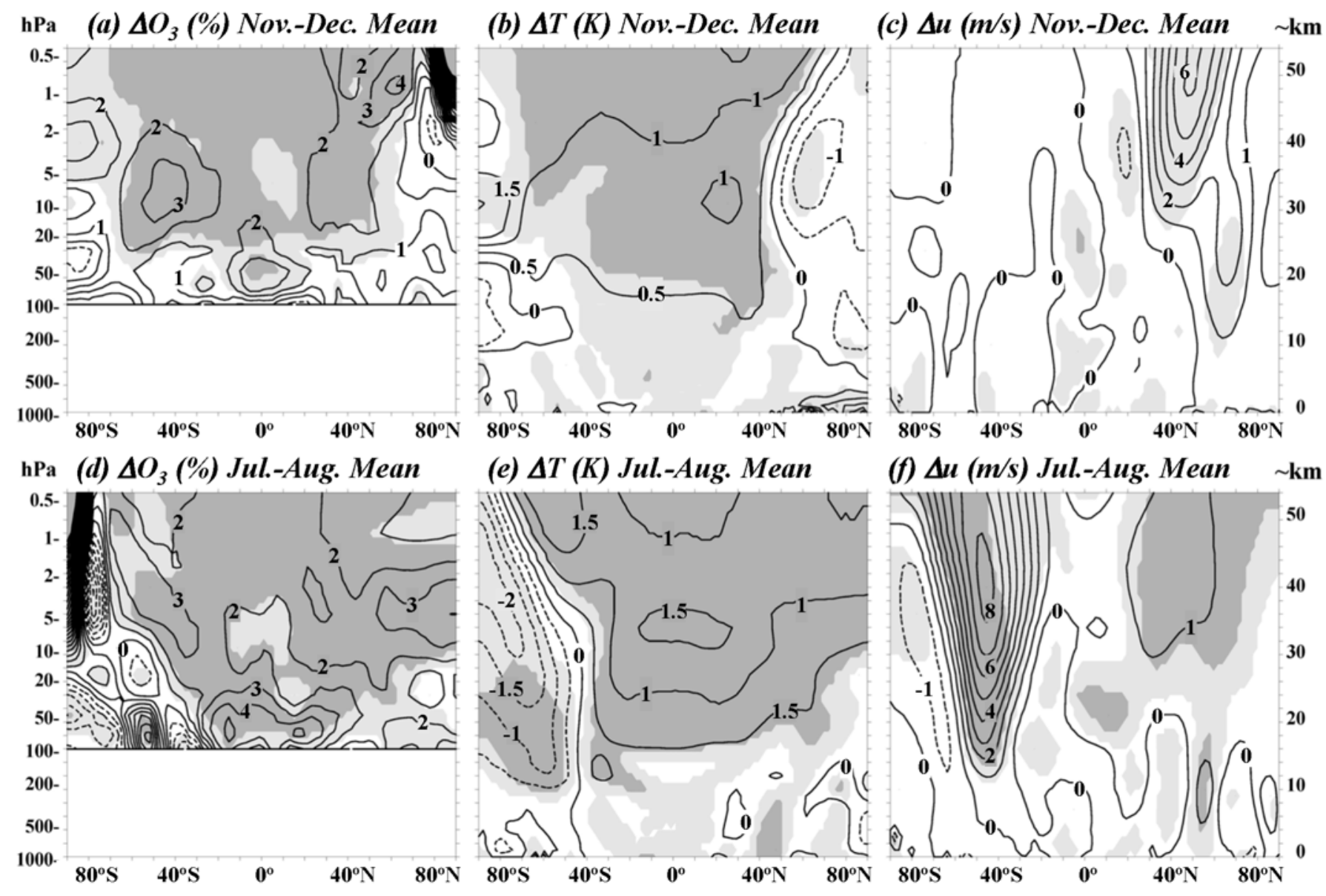

Figure 11. As in Figures 9 and 10 but for the single MRI-ESM1 simulation over the 19792005 period. 

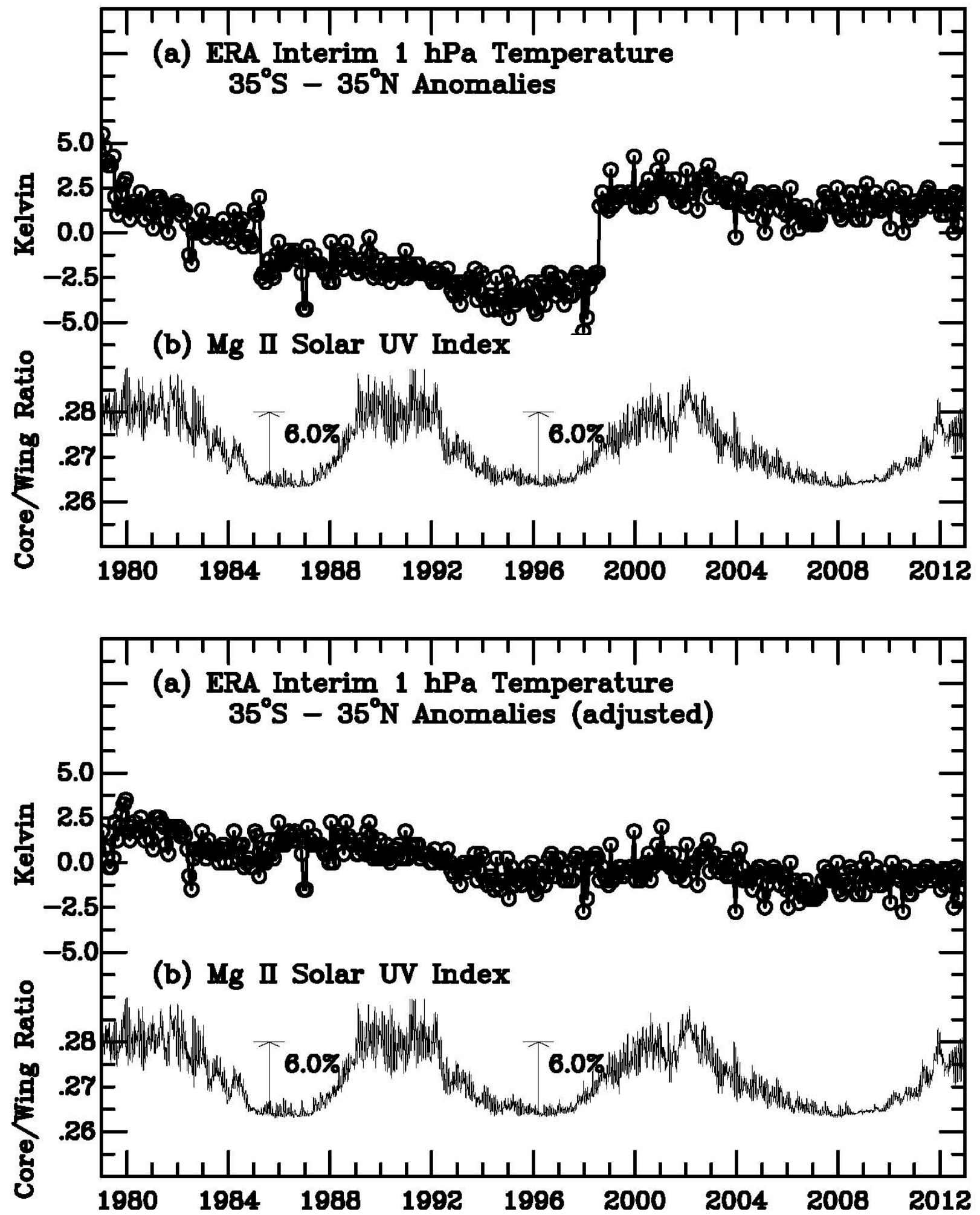

Figure A1. Top panel: (a) Area-weighted average over low latitudes of the ERA Interim $1 \mathrm{hPa}$ monthly temperature anomalies (deviations from long-term monthly means); (b) The Mg II core-to-wing ratio solar UV index. Bottom Panel: Same format as top panel but after offset adjustments are applied to the data (see the text). 